PLEASE NOTE:

This is the author's version of the manuscript accepted for publication in Cognition. Changes resulting from the publishing process, namely editing, corrections, final formatting for printed or online publication, and other modifications resulting from quality control procedures, may have been subsequently added.

The published version can be found in: Duncan, L. G., Castro, S. L., Defior, S., Seymour, P. H. K., Baillie, S., Leybaert, J., ... Serrano, F. (2013). Phonological development in relation to native language and literacy: Variations on a theme in six alphabetic orthographies. Cognition, 127(3), 398-419. doi: 10.1016/j.cognition.2013.02.009 


\title{
Phonological development in relation to native language and literacy: \\ Variations on a theme in six European languages
}

Lynne G. Duncana ${ }^{a^{*}}$, São Luís Castro ${ }^{\mathrm{b}}$, Sylvia Defior ${ }^{\mathrm{c}}$, Philip H.K. Seymoura, Sheila Baillie $^{a}$, Jacqueline Leybaertd, Philippe Moustyd ${ }^{\mathrm{d}}$ Nathalie Genardd ${ }^{\mathrm{d}}$, Menelaos Sarrise

Costas D. Porpodase, Rannveig Lundf, Baldur Sigurðssong, Anna S. Práinsdóttirg, Ana

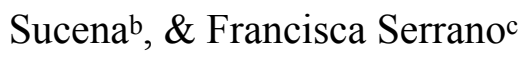

\author{
aUniversity of Dundee, UK \\ bUniversity of Porto, Portugal \\ c University of Granada, Spain \\ dFree University of Brussels, Belgium \\ eUniversity of Patras, Greece \\ ${ }^{\mathrm{f}}$ Reykjavik Academy, Iceland \\ $\mathrm{g}$ University of Education, Iceland
}

Running Head: Meta-phonological development in European languages

* Corresponding author 


\section{Introduction}

Two competing hypotheses about the relation between awareness of phonology and early reading are often described: (1) phonemic awareness precedes orthographic knowledge and helps in the formation of links between phonemes and graphemes; versus (2) phoneme awareness is acquired only as a result of learning about written graphemes. Although Castles and Coltheart (2004) criticised the pre-2004 evidence in support of each hypothesis, improved methodology in subsequent studies has shown that item-specific letter knowledge is not necessary for the emergence of phoneme awareness (Hulme, Caravolas, Malkova \& Brigstocke, 2005a) and that phoneme awareness is in fact beneficial for subsequent letter learning (Castles, Coltheart, Wilson, Valpied, \& Wedgwood, 2009). Of course, this does not rule out the possibility that in the normal course of beginning reading, letter knowledge also facilitates phoneme awareness; indeed, the evidence strongly implies that the relation between phonology and orthography is most likely bi-directional (Perfetti, Beck, Bell \& Hughes, 1987; Wagner, Torgesen \& Rashotte, 1994; Hulme, Snowling, Caravolas \& Carroll, 2005b).

Given that early training in phoneme awareness is rare and is regarded as having limited impact (e.g. Bus \& van Ijzendoorn, 1999; Castles et al, 2009), it is likely to be the influence of phonological skills at the outset of literacy acquisition that will be of most interest to researchers and educators. This has been expressed as the "availability" of phonology in Ziegler \& Goswami’s (2005) Psycholinguistic Grain Size model of reading development. This model also provides an excellent framework for exploring the later impact of orthography, in particular, the influence of the "granularity" of sound emphasised by the orthography and the "consistency" of 
the mapping between spelling and sound in shaping the course of further development. The aim of the present paper is to examine this interaction between phonological and orthographic development in six alphabetic orthographies during the first year of reading acquisition.

\section{Phonological Development}

\section{Theoretical background}

In formulating their description of the availability of phonology, Ziegler and

Goswami (2005) drew heavily on work in which phonological development has been characterised as a large-to-small sequence ((Treiman, 1985); (Fowler, 1991); (Metsala \& Walley, 1998). Their conclusion was that phonological development "can best be described along a continuum from shallow sensitivity of large phonological units to a deep awareness of small phonological units" (p.4).

In 1991, Fowler highlighted the increasingly segmental nature of speech perception between 3 and 7 years of age just as phonological awareness was emerging. The need to distinguish an increasing variety of words in the expanding lexicon is thought to alter the organisation of the speech system in successive steps, moving from a syllabic to an onset-rime level of organisation before finally settling at the phonemic level (Ferguson \& Farwell, 1975; Menyuk \& Menn, 1979; Jusczyk, 1986). This proposal has been formalised in the Lexical Restructuring model of phonological development (Walley, 1993; Metsala \& Walley, 1998), which makes a series of claims concerning phonological awareness and early reading: 1) there will be a specific relation between phonological development and early vocabulary growth reflecting such factors as sound-similarity relations between words; 2) lexical 
restructuring will bring about an increasingly segmental organisation in the lexicon which will be reflected in a large-to-small sequence in phonological skill; 3) initial phoneme awareness will reflect this restructuring process rather than general metacognitive ability or reading experience; and 4) this sequence is universal, at least for European languages (see also Anthony \& Francis, 2005; Ziegler \& Goswami, 2005). An alternative account by Gombert (1992) contrasts with this position in a number of ways. Firstly, the mechanism of change which produces representational redescription (Karmiloff-Smith, 1986) is not just vocabulary growth but rather, a wider interaction with the linguistic environment. Lexical information, initially stored in an implicit and instance-bound format, is gradually reorganised to produce a more flexible representational system which offers some degree of epi-linguistic control. This system remains inaccessible to conscious awareness until the presence of a specific demand in the external language environment provides the catalyst for metalinguistic (conscious) control to develop. Secondly, Gombert proposes that phonological development proceeds independently for each unit of sound, leaving open the possibility that a child could be in the more explicit meta-phase for phoneme awareness but remain in the implicit epi-phase for rhyme awareness (Duncan, Seymour, \& Hill, 1997). Thirdly, the overt dependence of Gombert's model on the particular language environment that is encountered creates the potential for alternative routes in phonological development according to the characteristics of a child's native language in both spoken and written forms. Evidence relating to these points of contrast between the models will be reviewed in the remainder of this section. 
Preliminary findings are inconclusive as to whether vocabulary growth drives a process of segmental restructuring, and hence, leads to the emergence of phoneme awareness. While McBride-Chang, Wagner, and Chang (1997) reported that vocabulary and phoneme awareness were related amongst beginning readers, both Elbro, Borstrom, and Petersen (1998) and Garlock, Walley and Metsala (2001) failed to replicate this finding. Furthermore, a relation between vocabulary and segmental representation within both adult and child samples was recently reported by Foy and Mann (2009), contradicting the idea of an age-related process of restructuring.

Nevertheless, Garlock et al (2001) documented a relationship between segmental processing and both word familiarity and neighbourhood density, which is consistent with other evidence that words from dense neighbourhoods are represented in greater phonological detail than those from sparse neighbourhoods (Metsala, 1999; De Cara \& Goswami, 2003). Unexpectedly, however, it appears to be the recognition of spoken words from sparse neighbourhoods that best predicts later phonological awareness (Garlock et al, 2001; Metsala, Stavrinos \& Walley, 2009), leading Metsala et al (2009) to propose variability in the representation of words from sparse neighbourhoods perhaps as a result of individual differences or because "there may be a critical point in vocabulary development when all words become phonemically analysed" (p. 116).

Indeed, fine-grained segmental restructuring has been observed in both literate and illiterate participants during normal language development, strengthening the view that lexical restructuring may be relatively independent of literacy acquisition and phonological awareness (Ventura, Kolinsky, Fernandes, Querido \& Morais, 2007). 
A large-to-small sequence in phonological development

Although tapping, blending, matching and oddity tasks generally reveal a high degree of preschool sensitivity to syllables and rimes (Goswami \& Bryant, 1990), the question of whether children show an earlier sensitivity to syllables than rimes as predicted by a large-to-small progression has not received a definitive answer. Carroll, Snowling, Hulme, and Stevenson (2003) failed to find any difference between syllables and rimes in a matching task across a four-month preschool period, but Anthony, Lonigan, Driscoll, Phillips and Burgess (2003) observed an overall advantage for syllables in blending and elision tasks in a large-scale study of 2- to 5year-olds.

Much may depend on the size of the sounds that are compared. Syllables are often described as larger than rimes but this is not necessarily the case since rimes can also be similar in size to syllables (e.g. chant vs. antler) or indeed larger than syllables (e.g. ramp vs. amber). When Treiman and Zukowski (1996) examined kindergartners' sensitivity to syllable and rime units of equivalent size in a word matching task, they found no advantage for syllables over rimes ${ }^{1}$.

On the other hand, rhyming skills are reliably found to be stronger than phoneme awareness prior to school entry (e.g. Bruce, 1964; Liberman, Shankweiler, Fischer, \& Carter, 1974; Read, 1978; Lenel \& Cantor, 1981; Bradley \& Bryant, 1983). However, this comparison frequently contains not just a contrast in sound (rimes vs. phonemes) but also a contrast in task (oddity or matching vs. deletion or segmentation). When the same task is used for each sound, accuracy can sometimes

\footnotetext{
1 Similarly, Savage, Blair, and Rvachew (2006) found equivalent matching accuracy for rimes ("bag-rag”) and
} similarly-sized head units ("dog-doll") amongst pre-readers. 
be higher for phonemes than onsets and rimes (Seymour \& Evans, 1994; Anthony et al, 2003).

The question of task demands is important as several authors have distinguished between a holistic (implicit) sensitivity to global sound similarity, sufficient for tasks such as oddity and matching, and more analytic (explicit) skills which seem to be required for deletion and segmentation (Morais, Alegria \& Content, 1987; Bertelson \& de Gelder, 1989, 1991; Morais, 1991; Gombert; 1992). Observations by Duncan et al. $(1997 ; 2000)$ were consistent with this distinction. Preschoolers exhibited the classic advantage for rimes over phonemes in an oddity task, indicative of excellent implicit rhyming skills, but on transfer to school, the children were mostly unable to identify the sound shared by rhyming word pairs like "boat-goat" in a common unit task ${ }^{2}$. This contrasted with the children's accuracy in identifying the shared phonemes in word pairs like "face-food" (see also: Seymour, Duncan \& Bolik, 1999; Goswami \& East, 2000). Similarly, Savage et al (2006) found a pre-reading advantage for larger over smaller units in matching but a small-unit advantage in common unit identification. Other preschool children with early reading skills showed a small-unit advantage in both implicit and explicit tasks.

Thus, the evidence implies that phonological development does not necessarily progress in a large-to-small sequence but may at times follow a small-tolarge path depending on the nature of the assessment task and the external demands placed upon the child. There is no provision for small-unit processing to emerge first in the Lexical Restructuring model but this possibility is compatible with Gombert's (1992) model.

\footnotetext{
2 This pattern is similar to the illiterate Brazilian poet described by Bertelson and de Gelder (1989) who composed poetry based on rhyme and showed perfect accuracy at implicit rhyme judgements and in producing rhyming words but was unable to isolate the shared parts of word-pairs which he had identified as rhyming or to explain why words rhyme (see also Morais et al, 1987).
} 
A universal sequence of phonological development

Evidence consistent with a large-to-small sequence has been observed in languages other than English. In studies using the same task to test awareness of syllables and phonemes, syllable awareness was found to be superior amongst French, Greek, Italian and Turkish kindergartners (Cossu, Shankweiler, Liberman \& Katz, 1988; Demont \& Gombert, 1996; Durgunoğlu \& Öney, 1999; Harris \& Giannouli, 1999; Aidinis \& Nunes, 2001)

Attempts to establish an intermediate status for rimes have met with more varied success. An intermediate status for rimes was suggested using oddity tasks in Dutch (de Jong \& van der Leij, 2003) but, in more explicit tasks, onsets and rimes did not seem especially cohesive and children often showed a preference for body-coda divisions (Geudens \& Sandra, 2003; Geudens, Sandra \& Van den Broeck, 2004; Geudens, Sandra \& Martensen, 2005). In Spanish, a large-to-small sequence in samedifferent matching became more evident for syllables and rimes when there was greater differentiation in the size and duration of these units (Goikoetxea, 2005; cf. Treiman \& Zukowski, 1991, 1996). These studies are consistent with the view that a more holistic awareness of sound is engaged in implicit phonological tasks which is sensitive to the size of the sounds under investigation (Morais et al, 1987; Bertelson \& de Gelder, 1989, 1991; Morais, 1991; Gombert; 1992).

In other work by Bertelson, de Gelder and van Zon (1997), second graders did not favour phonemes which were syllable onsets ( $\underline{\mathrm{CVCC}})$ over those which were part of an onset ( $\underline{\mathrm{CV}} \mathrm{C})$ in a comparison task, reinforcing the idea that the size rather than the status of the sound is important in such tasks, but these children were better at 
deleting the first consonant from CVCC structures than from CCVC structures (and kindergartners found this condition easier to learn).

Cross-linguistic variation has also been reported. Observations of higher levels of awareness of phonemes in complex onsets in Czech than in English have been attributed to the greater frequency of such structures in Czech (Caravolas \& Bruck, 1993). Italian and Turkish children have been found to be better at syllable and phoneme tapping than their English-speaking counterparts (Cossu et al, 1988; Durgunoğlu \& Öney, 1999). The higher levels of syllable awareness in Turkish, Italian, and also Greek, relative to languages like English and French have been linked to the simplicity of syllable structure and limited vowel repertoires in the former ${ }^{3}$ (Anthony \& Francis, 2005; Ziegler \& Goswami, 2005).

Exactly how cross-linguistic variation might be explained within the Lexical Restructuring model has yet to be clarified. One possibility is that cross-linguistic differences in the density of phonological neighbourhoods may cause variation in phonological development even though the pace of vocabulary growth may be similar across languages (Vicente, Castro \& Walley, 2003). A feature of languages containing simple syllable structures is the large number of polysyllabic words, whereas, languages with greater syllable complexity do not need to rely on syllable combination for lexical variety as variety can also exist via differences in syllable structure (Fenk-Oczlon \& Fenk, 1999). Vicente et al (2003) examined this in relation to European Portuguese which permits only simple CC clusters in the onset position and single $\mathrm{C}$ codas. As Portuguese vocabulary expands, more and more polysyllabic words are added to the lexicon, however, the majority of these words occupy sparse

\footnotetext{
3 Anthony and Francis (2005) further suggest that syllable boundaries in French and English are not well marked (p. 256) but these language are known to differ in this respect with clear syllable boundaries characteristic of French but not of English (e.g. Cutler, Mehler, Norris \& Seguí, 1986; Duncan, Colé, Seymour \& Magnan, 2006).
} 
phonological neighbourhoods. Vocabulary growth in English consists of the acquisition of shorter words with complex syllable structures ${ }^{4}$, many of which occupy relatively dense neighbourhoods. Thus, the pressure for lexical restructuring might be regarded as greater in English, and hence faster movement through the large-to-small sequence might be predicted in English than in languages with simpler syllable structures like Portuguese, Turkish or Italian. Nevertheless, faster restructuring also appears to imply an earlier competence in syllable awareness, whereas the opposite appears to be the case (Cossu et al, 1988; Durgunoğlu \& Öney, 1999).

An alternative possibility is that syllable structure effects might be related to speech rhythm (Ramus, Nespor, \& Mehler, 1999). Syllable structure together with patterns of vowel reduction and stress form the basis of several metrics of speech rhythm (Dauer, 1983; Ramus et al, 1999; Grabe \& Low, 2002), which have distinguished prototypical stress-timed languages like English, German and Dutch from syllable-timed languages like French, Italian and Spanish. Nevertheless, controversy exists as to the precise definition of speech rhythm (Kohler, 2009a), and it has variously been suggested that stress may underpin the rhythmic continuum (Dauer, 1983; Arvaniti, 2007), and that rhythm may not be completely signal-based, depending partially on perceptual grouping on the part of the listener (Lehiste, 1977; Dauer, 1983; Arvaniti, 1994; Lee \& Todd, 2004; Kohler, 2009b; Niebuhr, 2009). In spite of the controversies, however, there is considerable evidence that infant speech perception quickly tunes in to the rhythm of native language and that such effects persist in adult speech perception (Mehler, Dommergues, Frauenfelder, \& Segui, 1981; Nazzi, Bertoncini, \& Mehler, 1998; Murty, Otake \& Cutler, 2007; Kim, Davis \& Cutler, 2008). 
Duncan et al (2006) compared two languages with different rhythmic properties: English a stress-timed language with complex syllables, and French a syllable-timed language with simpler syllables (Abercrombie, 1967; Wioland, 1985). Preschoolers in each language accurately complied with instructions to break disyllabic words into two parts but only the French preschoolers broke the words reliably into two syllables. Thus, speech rhythm might be one aspect of the early linguistic environment which might produce variation in phonological development, which would be consistent with Gombert's (1992) model.

\section{Links between Phonology and Orthography}

\section{Theoretical background}

Literacy acquisition has also been implicated in phonological development as exposure to alphabetic reading instruction is thought to initiate a system of interactive links between orthography and phonology (Perfetti et al, 1987; Ehri, 1992; Wagner et al, 1994; Harm \& Seidenberg. 1999). These links inform not only the decoding process but also the spoken word recognition of adults and children (Ziegler \& Ferrand, 1998; Ventura, Morais \& Kolinsky, 2007). Of interest in the present context is the prospect that variation in the difficulty of the orthography being acquired can lead not only to cross-linguistic variation in reading progress but also to differences in the ease and speed of further phonological development (Cossu et al, 1988).

This concept of orthographic depth, first elaborated by Frost, Katz and Bentin (1987), proposes that alphabetic orthographies can be distinguished according to the "depth" or complexity of their letter-sound correspondences. In a shallow orthography, a direct 1-1 relation exists between the sounds in spoken words and the graphemes that represent those sounds, whereas, in a deep orthography, the relation 
between spelling and sound is more opaque. Thus, depth is equated with polyvalence (bi-directional one-to-many mapping) of grapheme-phoneme associations. Work conducted in the framework of connectionist modelling has defined depth in terms of the consistency of the pronunciations which occur for the orthographic rime segments of monosyllables (Treiman, Mullenix, Bjeljac-Babic, \& Richmond-Welty, 1995). Stone, Vanhoy \& van Orden (1997) distinguish between feedforward consistency (spelling-sound relationships) and feedback consistency (sound-spelling relationships), and such statistics have been calculated for English (Ziegler, Stone \& Jacobs, 1997) and for French (Ziegler, Jacobs \& Stone, 1996). These analyses indicate that the two languages are about equally inconsistent in the feedback direction (over 70 per cent of rimes have variable spellings) although English is more inconsistent than French in the feedforward direction (30 versus 12 per cent of rimes).

Such statistics have the potential to provide a metric of orthographic depth but are available for only a minority of European languages. To illustrate how the European languages might be classified along the dimensions of orthographic depth and syllable complexity, the EC network COST Action A8 which brought together researchers with an interest in reading acquisition and dyslexia produced the diagram in Figure 1 (Niessen, Frith, Reitsma, \& Öhngren, 2000). There was agreement that the shallow end includes: Finnish, Greek, Spanish, Icelandic, Norwegian and Swedish. Intermediate orthographies include Portuguese and French, and the deepest orthographies are Danish and English. Differences in syllabic structure are also included to show that the Germanic languages have many closed syllables with consonant clusters in both the onset and coda positions, whereas the remaining languages have a simpler structure with a preponderance of open syllables. 
Figure 1: COST A8 classification of languages in terms of orthographic depth and syllable structure*

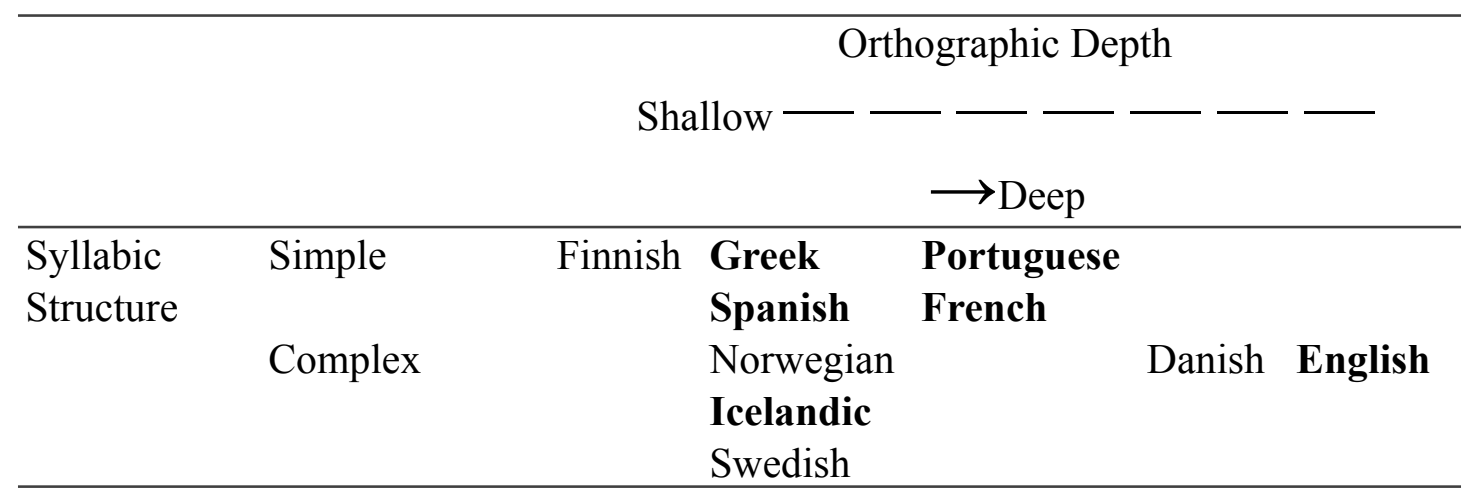

* The languages included in the present study are highlighted in bold

Subsequent work has been broadly in agreement with this classification except to suggest that French may be a deeper orthography than Portuguese and that Swedish may be deeper than Icelandic and Norwegian (Seymour et al, 2003; Borgwaldt, Hellwig \& De Groot, 2005). While progress in reading appears slower in deep orthographies like English (Seymour et al, 2003), it is not yet clear whether orthographic depth exerts any differential effects on the link between reading and phoneme awareness.

The influence of orthography is fundamental to the Psycholinguistic Grain Size model which predicts that phoneme awareness will only develop once children learn to read and write and that this process will be accelerated in languages with more consistent orthographies (Ziegler \& Goswami, 2005). The basis for this is the view that, prior to school entry, lexical restructuring will have resulted in a progression from the syllable to the onset-rime level of awareness and that further development will be accelerated in languages where consistent grapheme-phoneme correspondences reinforce the acquisition of phoneme awareness. In less consistent orthographies, grapheme-to-phoneme links are less reliable and more use may be 
made of larger rime-based decoding strategies in keeping with the level of consistency afforded by the rime unit in the orthography (Goswami, Porpodas \& Wheelwright, 1997; Goswami, Gombert \& de Barrera, 1998: Goswami, Ziegler, Dalton \& Schneider, 2001;Goswami, Ziegler, Dalton \& Schneider, 2003).

In English, consistency is greater when larger units are used for decoding (Treiman et al, 1995), but although it has been proposed that decoding begins at the level of the rime (see Goswami and Bryant (1990) for a review of this work and later work by Goswami (1990, 1991; Goswami \& Mead, 1992), other studies suggest that grapheme-phoneme decoding may be more usual amongst beginning readers (Ehri \& Robbins, 1992; Muter, Snowling \& Taylor, 1994; Bowey \& Underwood, 1996; Duncan et al, 1997) and that sensitivity to the consistency associated with rime units may develop later (Bowey \& Underwood, 1996; Brown \& Deavers, 1999; Duncan et al, 2000). What seems most likely is that this sequence can vary according to the sequence of decoding units taught in reading (Duncan et al, 1997, 2000; Goswami \& East, 2000). These latter findings are consistent with the role attributed by Gombert (1992) to external demands in determining which sounds children become explicitly aware of.

The impact of variation in orthographic depth is less well specified in Gombert's (1992) model but may form an additional aspect of the external demand of learning to read. Patel, Snowling and de Jong (2004) compared phoneme deletion skills between beginning readers of English (deep orthography) and Dutch (shallow orthography), observing equivalent accuracy but an RT advantage amongst older Dutch children. Caravolas, Volin and Hulme (2005) found that phoneme awareness was an important predictor of beginning reading in both English and the shallow Czech orthography, although accuracy was lower in English than in Czech. 
In a German-English comparison, Mann and Wimmer (2002) set out to contrast the prediction that early phoneme awareness would be driven by vocabulary growth and the lexical restructuring process (Metsala \& Walley, 1998), with the hypothesis that learning about letters and their sounds may promote phoneme awareness (Barron, 1991; Gombert, 1992). Equivalent vocabulary levels and hence, lexical restructuring were assumed because of the age-match. Letter knowledge was introduced in kindergarten in English but not in German, and an English advantage was observed at implicit phoneme identity judgements and at more explicit phoneme deletion. The German kindergartners were at chance on the implicit task in spite of normal oral language development. Thus, the outcome was most consistent with the influence of alphabetic knowledge as predicted in the Gombert (1992) model. As regards the benefit of learning a more transparent orthography like German, it may be that, once started, acquisition of phoneme awareness is accelerated relative to English ${ }^{5}$, although Mann and Wimmer note that in their study phonics instruction was more intensive in German.

\section{The present study}

The research to be presented here is a longitudinal study of phonological development in six European languages which aims to explore: a) the question of the availability of phonology in different languages at the outset of learning to read; and b) the influence of orthography (granularity, consistency) in shaping phonological development during the transition to literacy.

\footnotetext{
5 See Duncan et al (2006) for a similar result from a comparison of French and English.
} 
Availability of Phonology.

Phonological development will be tracked using two tasks: (1) Same-Different

Matching, which assesses more implicit sensitivity to phonological similarity; and (2)

Common Unit Identification, which requires more explicit manipulation of sound. A large-to-small (syllable $\rightarrow$ rime $\rightarrow$ phoneme) progression would be expected in each task according to Lexical Restructuring theory, however, Gombert's (1992) model does not predict a fixed order, only that implicit sensitivity to any sound is necessary (although not sufficient) for explicit awareness of that sound, and that some external demand is required for explicit awareness to emerge.

The question of cross-linguistic variation will be considered by comparison of phonological awareness amongst beginning readers of English, Greek, Icelandic, Portuguese, Spanish and French. In the Lexical Restructuring model, variation has only been discussed within-levels in the large-to-small sequence, giving rise to the suggestion that syllable and phoneme awareness each develop more quickly in languages with simple syllable structures (Anthony \& Francis, 2005; Ziegler \& Goswami, 2005). The languages under investigation here encompass a range of syllable complexity: English and Icelandic have the most complex syllables, French and Greek are intermediate and Spanish and, finally, Portuguese have the simplest structures (see Table 1). The implications of such variation for movement between levels have not been specified and lexical restructuring theory offers no reason to expect any interruption of the large-to-small sequence ${ }^{6}$.

${ }^{6}$ See discussion on pp. 9-11???? 
Table 1

Analysis of linguistic characteristics of participating languages (stress pattern, vowel reduction, syllable structure)

\begin{tabular}{|c|c|c|c|c|c|}
\hline & \multirow[t]{2}{*}{ Stress } & \multirow[t]{2}{*}{ Vowel Reduction } & \multicolumn{3}{|c|}{ Syllable Structure } \\
\hline & & & Onset & Coda & $\begin{array}{l}\text { \% Open } \\
\text { syllables }\end{array}$ \\
\hline English & Contrastive & Yes & $\mathrm{CCC}$ & $\mathrm{CCCC}$ & $44^{*}$ \\
\hline Icelandic & Fixed & No & $\mathrm{CCCC}$ & $\mathrm{CCC}$ & $?$ \\
\hline Greek & Contrastive & Yes $\dagger$ & $\mathrm{CCC}$ & $\mathrm{C} \S$ & $69 \#$ \\
\hline Portuguese & Contrastive & Yes & $\mathrm{CC}$ & $\mathrm{C}^{* *}$ & $81 * *$ \\
\hline Spanish & Contrastive & No & $\mathrm{CC}$ & $\mathrm{CC}$ & $70^{*}$ \\
\hline French & Fixed & No & $\mathrm{CCC}$ & $\mathrm{CC}$ & $74 *$ \\
\hline
\end{tabular}

* Dauer (1983)

\# Dauer (1980)

$\dagger$ Baltazani (2007) Arvaniti 07

§Mennen, Ineke and Areti Okalidou (2006) Acquisition of Greek phonology: an overview. QMU Speech Science Research Centre Working Papers, WP-11.

**Frota \& Vigario (2001)

Hayes 1985 -possible reference?

A more dynamic pattern is predicted by Gombert (1992) based on the idea that native language may shape meta-linguistic development. Speech rhythm offers an alternative conceptualisation of why phonological development might differ between the simple syllable Latinate languages and the more complex Germanic languages (Duncan et al, 2006). Nevertheless, other languages such as Greek and Portuguese have proved to have "mixed" or unclassifiable rhythm (Frota \& Vigario, 2001; Grabe \& Low, 2002), leading to controversy over how exactly to define the long-standing distinction between syllable-timed and stress-timed rhythm (Arvaniti, 2009; Kohler, 2009a,b). Until these issues are clarified, the present study will rely on the existing literature which consistently distinguishes the syllable-timed rhythm of French and Spanish from the stress-timed rhythm of English (Dauer, 1983; Ramus et al, 1999; 
Grabe \& Low, 2002) and most often places European Portuguese and Greek ${ }^{7}$ in an unclassified or intermediate category (Dauer, 1983; Frota \& Vigario, 2001; Grabe \& Low, 2002). Icelandic has not to our knowledge been studied in relation to speech rhythm and might be assumed to be stress-timed because of its Germanic origin and syllable complexity although the absence of vowel reduction and the fixed pattern of lexical stress differs from English, which may place it in an intermediate category instead.

Thus, the study will assess whether there is evidence of a large-to-small progression in phonological development, and whether any cross-linguistic variation that is observed is most consistent with an account emphasising syllable complexity (English, Icelandic $>$ French $>$ Greek $>$ Spanish $>$ Portuguese) or speech rhythm (English vs. Icelandic, Greek, Portuguese vs. French, Spanish). 


\section{Orthographic Depth}

In each of the participating countries in our study, information about letters and their sounds was introduced from the outset of the first year of schooling, and children were taught to use this information to decode written words. If letter-sound knowledge alone influences phonological development then the children have an equivalent exposure to this factor, but if the ease of decoding the orthography is important then the languages would be expected to differ according to their orthographic depth. A range in orthographic depth exists for each type of syllable structure in Figure 1, with English being deep relative to the other complex language, Icelandic, and both French and Portuguese being deeper than Greek and Spanish.

Thus, the Psycholinguistic Grain Size Model predicts a large-to-small sequence in explicit sensitivity to sound, whereas an increase in explicit awareness of phonemes regardless of the other units is expected in response to phonics instruction in Gombert's model (1992). The Psycholinguistic Grain Size Model additionally predicts that phoneme awareness may be accelerated in shallow relative to deeper orthographies (Greek, Spanish, Icelandic $>$ Portuguese $>$ French $>$ English).

\section{Method}

\section{Participants}

All testing took place in Primary schools that were located in small towns and had middle-class catchment areas. Children from six countries (Belgium, Greece, Iceland, Portugal, Spain and the United Kingdom) enabled comparison of reading development in the following languages: English, Greek, Icelandic, Portuguese, Spanish and French. The phonological assessments were administered at the beginning of the first school year (Time 1) after one month of schooling, and at the 
end of the first year (Time 2) after ten months of schooling. The first testing point was delayed by approximately 2 weeks in Belgium but the second testing point was completed at the same time as the other groups.

Of importance is the early age at which reading instruction commences in the UK relative to other European countries (Table 3). The UK children were 5 years old at the beginning of the first school year, whereas all of the other language groups were aged 6 years and did not differ from each other in this respect $(\mathrm{F}<1)$.

\section{Materials and procedure}

\section{Phonological tasks}

As the prevalence of monosyllables in English is unusually high, our investigation focused on disyllabic words which are more typical across all of the languages in our study. All phonological units occurred in the initial syllable on the basis that children are sensitive to the hierarchical structure of syllables and that each syllable is most easily divisible into onsets and rimes and only then into phonemes (Treiman, 1992) ${ }^{8}$. The most typical stress pattern for disyllabic words was used in each language (e.g. English, Greek, Icelandic, Spanish, Portuguese ????? initial stress; French, final stress). Three sets of 8 word-pairs were constructed according to the shared unit under examination: syllable, rime or phoneme (see Table 2) ${ }^{9}$. All words were selected to be in the oral vocabularies of the beginning readers. Each set of words-pairs contained an equal number of CV (open) and CVC (closed) initial syllables, except in Greek and Icelandic where the CVC condition proved difficult to form. To enable a balance in

\footnotetext{
${ }^{8}$ See Duncan, Seymour and Bolik (2007) for a discussion of how rime-based theories of word recognition might translate to a disyllabic context.

${ }^{9}$ Note that English examples are used throughout but targets and foils were formed according to the same principles in each language. Phonetic transcriptions and syllabifications were checked using the Oxford English Dictionary and the CELEX database.
} 
terms of number of items, the CVC condition for each sound contained two CVC and two CV structures in Greek, and three CVC and one CV structure for the syllable and phoneme conditions in Icelandic. The shared sound was the only sound shared by the two words

\section{Table 2}

Structure of target stimuli used in the phonological tasks

\begin{tabular}{l}
\hline \multicolumn{3}{|l|}{ Sound } \\
\hline
\end{tabular}

The set of target pairs were used in both tasks and the Same-Different task additionally had 24 foil pairs with no sounds in common (e.g. fountain-shoulder

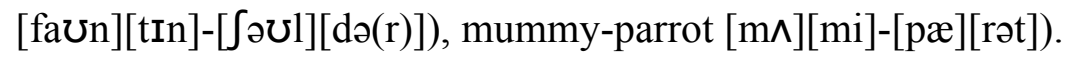

Same-Different Matching Task Procedure. A demonstration item was used to introduce a puppet who liked word-pairs which had the same sound. The child was then asked to make the puppet repeat a word-pair spoken by the experimenter and the experimenter repeated the pair a second time. The child responded by making the puppet choose either a happy or a sad face printed on cards in front of them according to whether or not the puppet liked the sound of the words. Corrective feedback was given on the two practice items when the experimenter emphasised the shared sound 
orally but did not segment the shared sound. Encouragement was given on the experimental trials but no feedback.

Same-Different matching scores were analysed using the hits-false alarms index from Signal Detection theory to calculate mean percentage accuracy rates which are corrected for guessing (Green \& Swets, 1966).

Common Unit Task Procedure. It was explained that a different puppet likes to say the little bits of words that sound the same. For the demonstration item, the experimenter said a word-pair aloud and then made the puppet repeat the sound that the words had in common. The practice and experimental trials had the same format except that corrective feedback was given during practice. The child was asked to help the puppet to tell the experimenter "Which bit sounds the same in....?" On each trial, the experimenter said the word-pair aloud and repeated it again before the child answered.

The items for each task were presented in blocks by condition, each in a separate testing session, and the order of the conditions was counterbalanced over participants in each country with the provision that all of the same-different matching conditions were presented before common unit conditions to avoid drawing children's attention artificially to segments of sound in the matching task. 


\section{Literacy and ability measures}

These assessments were part of a larger battery of tests administered during the longitudinal study of the first year of reading acquisition. At the end of this year (Time 2), the WISC-R Digit Span (forwards and backwards) and the Raven's Progressive Coloured Matrices were examined.

Test of upper- and lower-case letter knowledge, simple word reading and monosyllabic nonword naming were administered via computer at Time 1 and Time 2. The simple words varied in length but all had a consistent 1:1 relationship between letters and sounds (e.g. dog, sun, dragon). Nonwords were monosyllabic with one of three different structures: CV, VC or CVC. Cognitive Workshop software developed at the Universities of Dundee in the United Kingdom and Jyväskylä in Finland was used to run the experiments in each country. The procedure was the same for each task: stimuli in 48 point Times New Roman font were presented centrally, preceded by a $1000 \mathrm{~ms}$ central fixation and a $1000 \mathrm{~ms}$ blank screen, and remained on the screen until a vocal response was made, or for $10000 \mathrm{~ms}$. Accuracy was recorded by the experimenter and a voice key was used to register reaction time. Reaction times (and also accuracy) were later verified manually using Sound Forge Digital Sound Editing software (version 4.0). 
Table 3

Chronological Age in Months and Mean Percentage Accuracy for Upper-and LowerCase Letter Knowledge, Simple Word Reading and Monosyllabic Nonword Naming for each Language at Time 1 (Standard Deviations in Parentheses)

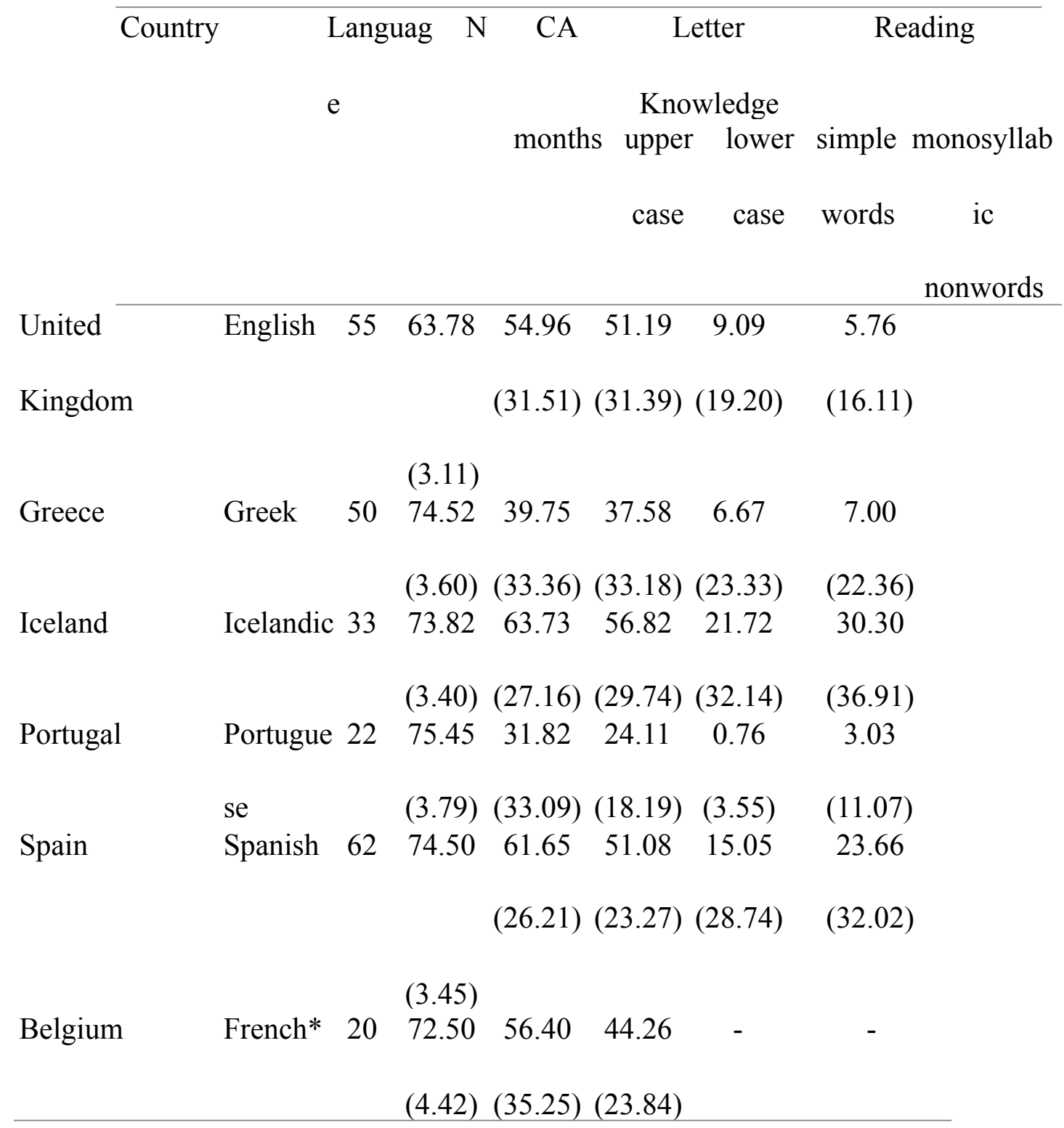

* Reading data were not available for French 
Results

Time 1: Start of Grade 1

Table 3 contains the mean percentage accuracy scores for the letter identification and reading tasks. For letters, significant differences emerged in one-way ANOVAs between languages on upper-case, $F(5,236)=5.90, p<.001, \eta_{\mathrm{p}^{2}}=.11$, and lowercase letter knowledge, $F(5,236)=5.34, p<.001, \eta_{\mathrm{p}}^{2}=.10$. Tukey HSD tests $(\alpha<.05$, throughout) showed a similar pattern for both cases with lowest scores in Portuguese. Greek performance overlapped both with the Portuguese group and with the four remaining groups. The English children did not appear to be disadvantaged by being a year younger as they were among the high performers who knew approximately $50-60 \%$ of the letters after one month of schooling.

There were significant group differences in both the simple word, $F(4,217)=$ $3.43, p<.05, \eta_{\mathrm{p}}{ }^{2}=.06$, and nonword reading tasks, $F(4,217)=8.61, p<.001, \eta_{\mathrm{p}}^{2}=$. 14. There was a lot of overlap between the groups in simple word reading and only the high-scoring Icelandic children could be distinguished from the Portuguese children. However, there were two clear groups for nonword naming: Portuguese, English, Greek $<$ Spanish, Icelandic.

\section{Same-Different Matching}

Mean percentage accuracy for Same-Different matching in each language is shown in Table 4. A three-way ANOVA with between-participants factor, language (English, Greek, Icelandic, Portuguese, Spanish, French) and within-participants factors, unit (syllable, rime, phoneme) and structure $(\mathrm{CVC}, \mathrm{CV})$, indicated that all main effects were significant (language: $F(5,236)=9.45, p<.001, \eta_{\mathrm{p}}{ }^{2}=.17$; unit: $F(2,472)=$ $112.53, p<.001, \eta_{\mathrm{p}}{ }^{2}=.32$; structure: $\left.F(1,236)=17.19, p<.001, \eta_{\mathrm{p}}{ }^{2}=.07\right)$. The 
interaction structure by language was marginal, $F(5,236)=2.01, p=.07$, but the other two-way interactions were significant (unit by language: $F(10,472)=3.11, p<$. $01, \eta_{\mathrm{p}}^{2}=.06$; unit by structure: $\left.F(2,472)=15.24, p<.001, \eta_{\mathrm{p}}{ }^{2}=.06\right)$. The three-way interaction unit by structure by language was also significant, $F(10,472)=3.25, p<$. $001, \eta_{\mathrm{p}}{ }^{2}=.06$, and the experiment was initially interpreted at this level to examine how item structure affected responses.

Simple effects showed that sounds appeared more salient in larger CVC structures: this applied to all units in Greek, $F(1,49)=13.41, p<.01$, but just to rimes in Portuguese, $F(2,42)=7.26, p<.01$, Spanish, $F(2,122)=12.08, p<.001$, and French: $F(2,38)=3.40, p<.05)$. Only the Spanish group showed a significant effect of structure for phonemes (more salient in $\mathrm{CV}$ than $\mathrm{CVC}$ ). No effects of structure were found in English and Icelandic.

Simple effects were also used to examine the theoretically important unit by language interaction, revealing significant effects of unit for all languages (English: $F(2,108)=18.61, p<.001 ;$ Greek: $F(2,98)=34.62, p<.001 ;$ Icelandic: $F(2,64)=$ 12.86, $p<.001$; Portuguese: $F(2,42)=15.76, p<.001$; Spanish: $F(2,122)=40.10, p$ $<.001$; French: $F(2,38)=31.56, p<.001)$. English and Greek showed a similar pattern: syllables $>$ phonemes $>$ rimes. Icelandic, Portuguese, Spanish and French all showed a different pattern: syllables $>$ rimes $=$ phonemes $($ Figure $2(a))$. 
Table 4

Mean Percentage Accuracy for Same-Different Matching in each Language at Time 1 (Standard Deviations in Parentheses)

\begin{tabular}{|c|c|c|c|c|c|c|c|c|}
\hline \multirow[t]{2}{*}{ Time } & \multirow[t]{2}{*}{ Unit } & \multirow{2}{*}{$\begin{array}{l}\text { Structu } \\
\text { re }\end{array}$} & \multicolumn{6}{|c|}{ Language } \\
\hline & & & $\begin{array}{c}\text { Englis } \\
\mathrm{h} \\
(\mathrm{n}=55)\end{array}$ & $\begin{array}{l}\text { French } \\
(n=20)\end{array}$ & $\begin{array}{l}\text { Greek } \\
(n=50)\end{array}$ & $\begin{array}{l}\text { Icelandic } \\
(n=33)\end{array}$ & $\begin{array}{c}\text { Portugues } \\
\text { e } \\
(n=22)\end{array}$ & $\begin{array}{c}\text { Spanish } \\
(n=62)\end{array}$ \\
\hline
\end{tabular}

Start of Grade

1

$\begin{array}{lccccccc}\text { Syllabl } & \text { CVC } & 46.36 & 76.23 & 61.00 & 75.76 & 65.91 & 70.97 \\ \mathrm{e} & & (40.66 & (37.59) & (44.37) & (32.57) & (36.63) & (33.02) \\ & & & & & & \\ & \text { CV } & 41.36 & 76.19 & 47.00 & 66.67 & 67.05 & 68.55 \\ & & (41.17 & (28.67) & (40.92) & (35.17) & (37.31) & (33.25) \\ & & & & & & & \end{array}$

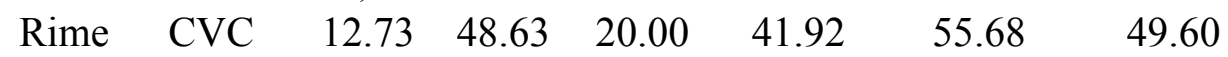

$\begin{array}{lllll}(17.26 & (34.88) & (28.57) & (30.93) & (30.79)\end{array}$

)

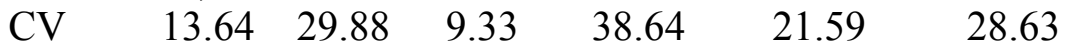

$\left.\begin{array}{llll}20.31 & (20.81)(17.87) & (30.03) & (24.76)\end{array}\right)$

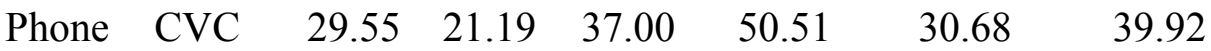

me $\quad\left(\begin{array}{lllll}40.28 & (28.39) & (37.54) & (32.87) & (34.44)\end{array}\right.$

$\begin{array}{lllllll}\mathrm{CV} & 31.82 & 33.70 & 31.00 & 50.76 & 31.82 & 50.81\end{array}$

$\begin{array}{lllll}40.38 & (35.60)(35.32) & (37.23) & (31.98) & (28.62)\end{array}$

On syllables, English performance was significantly worse than Spanish, Icelandic and French (all three equal), with Greek and Portuguese overlapping both groups $F(5,236)=5.41, p<.001)$. On rimes, English and Greek performance was equivalent and significantly worse than all the other languages, $F(5,236)=20.53$, $p<$ .001. A different pattern emerged for phonemes with the only significant difference being that between French (low) and Icelandic (high), $F(5,236)=3.14, p<.01$. 
28 in 59 
Figure 2: $\quad$ Percentage accuracy in phonological awareness tasks for each language group at the beginning of Grade 1: (a) Same-Different Task; (b) Common Unit task.

(a)
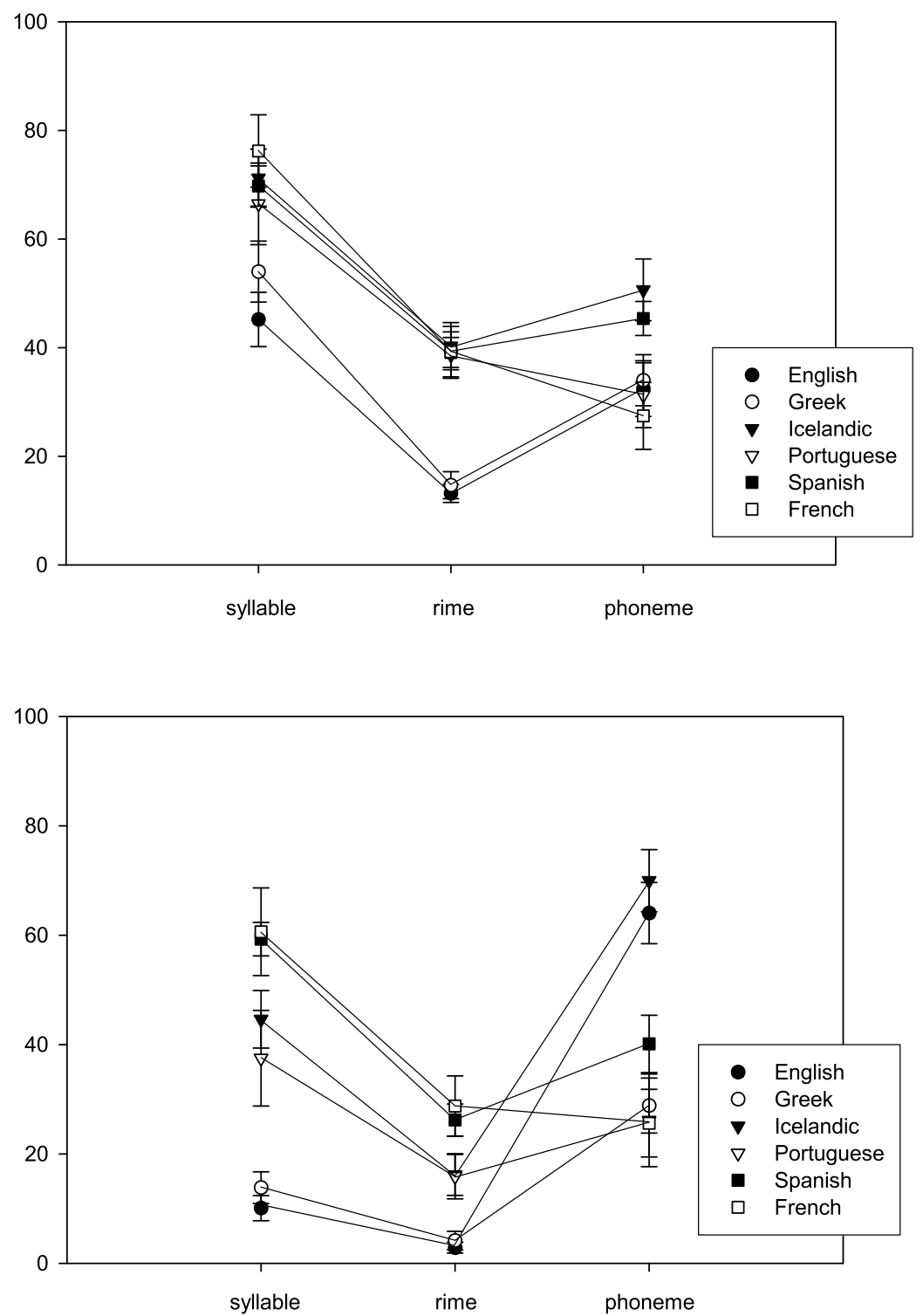
Common Unit Task

Table 5

Mean Percentage Accuracy for Common Unit Identification in each Language at

Time 1 (Standard Deviations in Parentheses)

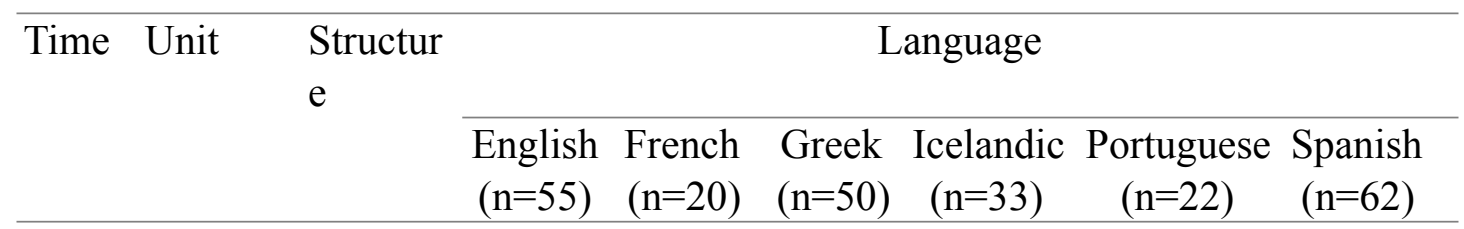

Start of Grade 1

\begin{tabular}{|c|c|c|c|c|c|c|c|}
\hline \multirow[t]{3}{*}{ Syllable } & $\mathrm{CVC}$ & $\begin{array}{c}9.55 \\
(20.12)\end{array}$ & $\begin{array}{c}52.50 \\
(38.81)\end{array}$ & $\begin{array}{c}5.00 \\
(20.82)\end{array}$ & $\begin{array}{c}32.42 \\
(29.34)\end{array}$ & $\begin{array}{c}29.55 \\
(39.82)\end{array}$ & $\begin{array}{r}29.03 \\
(38.73)\end{array}$ \\
\hline & $\mathrm{CV}$ & 9.55 & 68.75 & 22.67 & 56.82 & 45.45 & 89.52 \\
\hline & & (18.31) & (39.63) & $(32.25)$ & (37.64) & $(47.3$ & 20 \\
\hline \multirow[t]{4}{*}{ Rime } & $\mathrm{CVC}$ & 2.73 & 5.00 & 3.00 & 8.84 & 4.55 & 8.06 \\
\hline & & (11.46) & (13.08) & (11.99) & (17.67) & $(9.87)$ & (19.6 \\
\hline & $\mathrm{CV}$ & 2.73 & 52.50 & 5.33 & 23.48 & 27.27 & 44.3 \\
\hline & & $(7.87)$ & (42.07) & (14.85) & (33.04) & (34.42) & (36.3 \\
\hline \multirow{4}{*}{$\begin{array}{l}\text { Phonem } \\
\text { e }\end{array}$} & CVC & 64.09 & 30.00 & 33.00 & 71.72 & 26.14 & 37.1 \\
\hline & & $(43.50)$ & $(28.79)$ & (39.91) & (34.48) & (40.44) & $(42.6$ \\
\hline & $\mathrm{CV}$ & 61.36 & 21.25 & 24.67 & 68.18 & 26.14 & 43.1 \\
\hline & & (43.52) & (29.55) & (34.87) & (34.95) & (39.70) & $(41.7$ \\
\hline
\end{tabular}

Despite the slight tendency to floor effects in the CVC version of the rime condition

(Table 5), an ANOVA was conducted with between-participants factor, language

(English, Greek, Icelandic, Portuguese, Spanish, French) and within-participants

factors, unit (syllable, rime, phoneme) and structure (CVC, CV). All main effects

were significant: language $\left(F(5,236)=15.08, p<.001, \eta_{\mathrm{p}^{2}}=.24\right)$; unit $(F(2,472)=$

59.18, $\left.p<.001, \eta_{\mathrm{p}}{ }^{2}=.20\right)$; and structure $\left(F(1,236)=136.91, p<.001, \eta_{\mathrm{p}}{ }^{2}=.37\right)$. All

two-way interactions were significant (unit by language: $F(10,472)=17.72, p<.001$,

$\eta_{\mathrm{p}}^{2}=.27$; structure by language: $F(5,236)=33.15, p<.001, \eta_{\mathrm{p}}{ }^{2}=.41 ;$ unit by

structure: $\left.F(2,472)=58.75, p<.001, \eta_{\mathrm{p}}^{2}=.20\right)$. The three-way interaction, language 
by unit by structure $\left(F(10,472)=9.53, p<.001, \eta_{\mathrm{p}}^{2}=.17\right)$ was also significant and simple effects were applied to investigate the influence the effect of structure on shared unit identification in each language.

There was no effect of structure in English but the other languages found it easier to identify shared syllables and rimes in small CV structures (Icelandic: $F(2$, $64)=9.14, p<.001$; Portuguese: $F(2,42)=4.10, p<.05$; Spanish: $F(2,122)=48.47$, $p<.001$; French: $F(2,472)=23.42, p<.001)$. This effect only applied to syllables in Greek, $F(2,472)=12.59, p<.001$. Phoneme identification was not affected by structure in English, Icelandic and Portuguese but an advantage emerged for CVC structures in Greek and French and for CV structures in Spanish.

Investigation of the important unit by language interaction using simple effects showed an effect of unit in all languages (English: $F(2,108)=89.65, p<.001$; Greek: $F(2,98)=14.83, p<.001 ;$ Icelandic: $F(2,64)=48.49, p<.001 ;$ Portuguese: $F(2,42)$ $=3.29, p<.05$; Spanish: $F(2,122)=19.36, p<.001$; French: $F(2,38)=10.74, p<$. 001). Accuracy was higher for phonemes than rimes in English, Greek and Icelandic, and phonemes were also more salient than syllables in English and Icelandic. Syllable identification was better than rime identification in Icelandic and Portuguese. Syllables were easiest in Spanish and French and accuracy did not differ between phonemes and rimes.

Comparison between languages reveals clear accuracy differences between English and Greek (low) and Spanish and French (high) in relation to syllables $(F(5$, $236)=32.47, p<.001)$ and rimes $(F(5,236)=15.79, p<.001)$. Icelandic and Portuguese fall into an intermediate grouping for syllables and rimes, with Icelandic overlapping with Spanish and French for syllables and both Icelandic and Portuguese overlapping with all the other languages in response to rimes (see Figure 2(b)). The 
effect of language is noticeably different for phonemes, $F(5,236)=9.25, p<.001$.

Accuracy is highest in English and Icelandic, with French, Portuguese and Greek least accurate and Spanish intermediate as Spanish overlaps with each set.

\section{Relation with Orthography}

Combining the data from all of the language groups, hierarchical multiple regression was used to examine the relationship between letter knowledge (upper and lower case) and implicit and explicit task accuracy for each sound at the start of the school year, after controlling for ability measures (Ravens and Digit Span) taken at the end of the year (see results (a) in Table 6. The effect of language/orthography was entered as a dummy variable.

\section{NB. English results ONLY in black (Greek, Icelandic, English \& Portuguese in red)}

Letter knowledge was not found to contribute to rime awareness in either the Matching or Common Unit tasks. However, letter knowledge did explain significant variance in syllable matching (14\%) although not in the common unit task. In each task, letter knowledge made the strongest contribution to phoneme awareness (matching: 22\%; common unit: 16\%). In a second series of analyses of phonemic skills, the concurrent contribution of syllable awareness was entered as an intermediate step for each task (see results (b) in Table???). While syllable matching was a highly significant predictor of phoneme matching, syllable common unit identification did not predict the identification of common phonemes. 
Hierarchical Multiple Regression

(a)

\begin{tabular}{|c|c|c|c|c|}
\hline \multicolumn{5}{|c|}{ Dependent variable: syllable matching } \\
\hline Step & Variables & $\Delta \mathrm{R}^{2}$ & $\mathrm{~F}$ & $\mathrm{p}$ \\
\hline 1 & $\begin{array}{l}\text { T3 Ravens } \\
\text { T3 Digit Span }\end{array}$ & $\begin{array}{l}16 \% \\
12 \%\end{array}$ & $\begin{array}{l}4.97 \\
10.76\end{array}$ & $\begin{array}{l}* \\
* * *\end{array}$ \\
\hline 2 & $\begin{array}{l}\text { T0 upper } \\
\text { T0 lower }\end{array}$ & $\begin{array}{l}14 \% \\
7 \%\end{array}$ & $\begin{array}{l}4.84 \\
6.71\end{array}$ & $\begin{array}{l}* \\
* *\end{array}$ \\
\hline \multicolumn{5}{|c|}{ Dependent variable: rime matching } \\
\hline 1 & $\begin{array}{l}\text { T3 Ravens } \\
\text { T3 Digit Span }\end{array}$ & $\begin{array}{l}5 \% \\
11 \%\end{array}$ & $\begin{array}{l}1.22 \\
9.62\end{array}$ & $\begin{array}{l}\text { n.s. } \\
* * *\end{array}$ \\
\hline 2 & $\begin{array}{l}\text { T0 upper } \\
\text { T0 lower }\end{array}$ & $\begin{array}{l}1 \% \\
2 \%\end{array}$ & $\begin{array}{l}<1 \\
1.74\end{array}$ & $\begin{array}{l}\text { n.s. } \\
\text { n.s. }\end{array}$ \\
\hline \multicolumn{5}{|c|}{ Dependent variable: phoneme matching } \\
\hline 1 & $\begin{array}{l}\text { T3 Ravens } \\
\text { T3 Digit Span }\end{array}$ & $\begin{array}{l}13 \% \\
17 \%\end{array}$ & $\begin{array}{l}3.72 \\
15.59\end{array}$ & $\begin{array}{l}* \\
* * *\end{array}$ \\
\hline 2 & $\begin{array}{l}\text { T0 upper } \\
\text { T0 lower }\end{array}$ & $\begin{array}{l}22 \% \\
18 \%\end{array}$ & $\begin{array}{l}8.21 \\
21.20\end{array}$ & $\begin{array}{l}* * * \\
* * *\end{array}$ \\
\hline
\end{tabular}

(b)

\begin{tabular}{|l|l|l|l|l|}
\hline \multicolumn{5}{|c|}{ Dependent variable: syllable common unit } \\
\hline Step & Variables & $\Delta \mathrm{R}^{2}$ & $\mathrm{~F}$ & $\mathrm{p}$ \\
\hline 1 & T3 Ravens & & & \\
& T3 Digit Span & $5 \%$ & 1.23 & n.s. \\
& & $19 \%$ & 17.67 & $* * *$ \\
\hline 2 & T0 upper & & & \\
& T0 lower & $1 \%$ & $<1$ & n.s. \\
& & $2 \%$ & 1.58 & n.s. \\
\hline & & & & \\
\hline
\end{tabular}

Dependent variable: rime common unit

\begin{tabular}{|c|c|c|c|c|}
\hline 1 & $\begin{array}{l}\text { T3 Ravens } \\
\text { T3 Digit Span }\end{array}$ & $\begin{array}{l}6 \% \\
12 \% \\
\end{array}$ & $\begin{array}{l}1.58 \\
10.79 \\
\end{array}$ & $\begin{array}{l}\text { n.s. } \\
* * *\end{array}$ \\
\hline 2 & $\begin{array}{l}\text { T0 upper } \\
\text { T0 lower }\end{array}$ & $\begin{array}{l}0 \% \\
1 \%\end{array}$ & $\begin{array}{l}<1 \\
<1\end{array}$ & $\begin{array}{l}\text { n.s. } \\
\text { n.s. }\end{array}$ \\
\hline \multicolumn{5}{|c|}{ Dependent variable: phoneme common unit } \\
\hline 1 & $\begin{array}{l}\text { T3 Ravens } \\
\text { T3 Digit Span }\end{array}$ & $\begin{array}{l}18 \% \\
7 \%\end{array}$ & $\begin{array}{l}5.75 \\
5.61\end{array}$ & $\begin{array}{l}* * \\
* *\end{array}$ \\
\hline 2 & $\begin{array}{l}\text { T0 upper } \\
\text { T0 lower }\end{array}$ & $\begin{array}{l}16 \% \\
25 \%\end{array}$ & $\begin{array}{l}6.18 \\
27.88\end{array}$ & $\begin{array}{l}* * \\
* * *\end{array}$ \\
\hline
\end{tabular}

\begin{tabular}{|l|l|l|l|l|}
\hline \multicolumn{5}{|l|}{ Dependent variable: phoneme common unit } \\
\hline Step & Variables & $\Delta \mathrm{R}^{2}$ & $\mathrm{~F}$ & $\mathrm{p}$ \\
\hline 1 & T3 Ravens & $18 \%$ & 5.75 & $* *$ \\
& T3 Digit Span & $7 \%$ & 5.61 & $* *$ \\
\hline 2 & T0 Syllable & & & \\
& common unit & $2 \%$ & 1.49 & n.s. \\
& & $3 \%$ & 5.47 & $*$ \\
\hline 3 & T0 upper & & & \\
& T0 lower & $16 \%$ & 6.32 & $* *$ \\
& & $24 \%$ & 27.95 & $* * *$ \\
\hline
\end{tabular}

\begin{tabular}{|c|c|c|c|c|}
\hline \multicolumn{5}{|c|}{ Dependent variable: phoneme matching } \\
\hline Step & Variables & $\Delta \mathrm{R}^{2}$ & $\mathrm{~F}$ & $\mathrm{p}$ \\
\hline 1 & $\begin{array}{l}\text { T3 Ravens } \\
\text { T3 Digit Span }\end{array}$ & $\begin{array}{l}13 \% \\
17 \%\end{array}$ & $\begin{array}{l}3.72 \\
15.59\end{array}$ & $\begin{array}{l}* \\
* * *\end{array}$ \\
\hline 2 & $\begin{array}{l}\text { T0 Syllable } \\
\text { matching }\end{array}$ & $\begin{array}{l}37 \% \\
25 \%\end{array}$ & $\begin{array}{l}36.61 \\
64.42\end{array}$ & $\begin{array}{l}* * * \\
* * *\end{array}$ \\
\hline 3 & $\begin{array}{l}\text { T0 upper } \\
\text { T0 lower }\end{array}$ & $\begin{array}{l}6 \% \\
10 \%\end{array}$ & $\begin{array}{l}3.23 \\
15.07\end{array}$ & $\begin{array}{l}* \\
* * *\end{array}$ \\
\hline
\end{tabular}


Figure 3 - data from all language groups (letter knowledge on y-axis)

Phoneme Matching

\section{Common Unit}
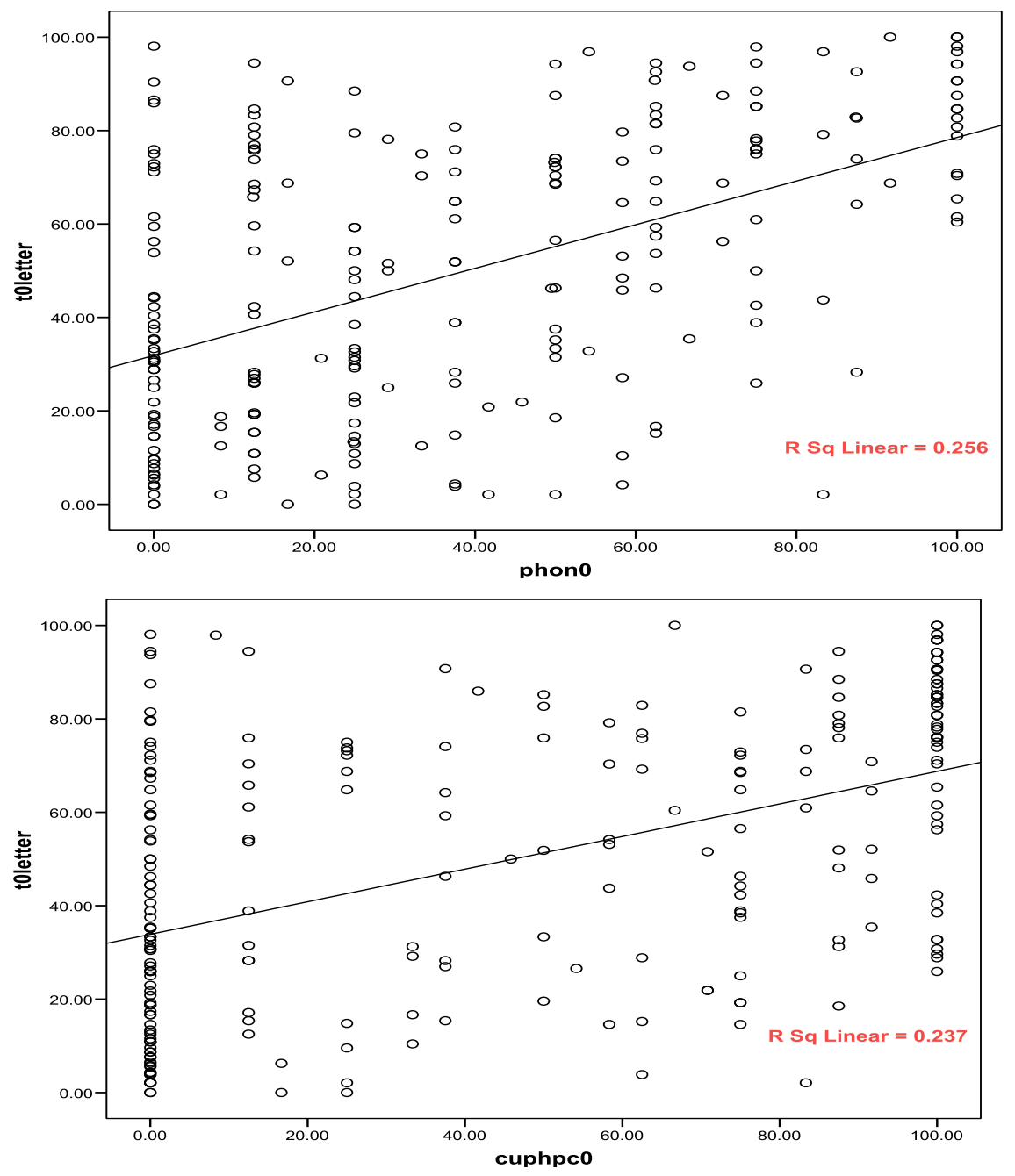

Simple word reading

word reading

Phoneme 

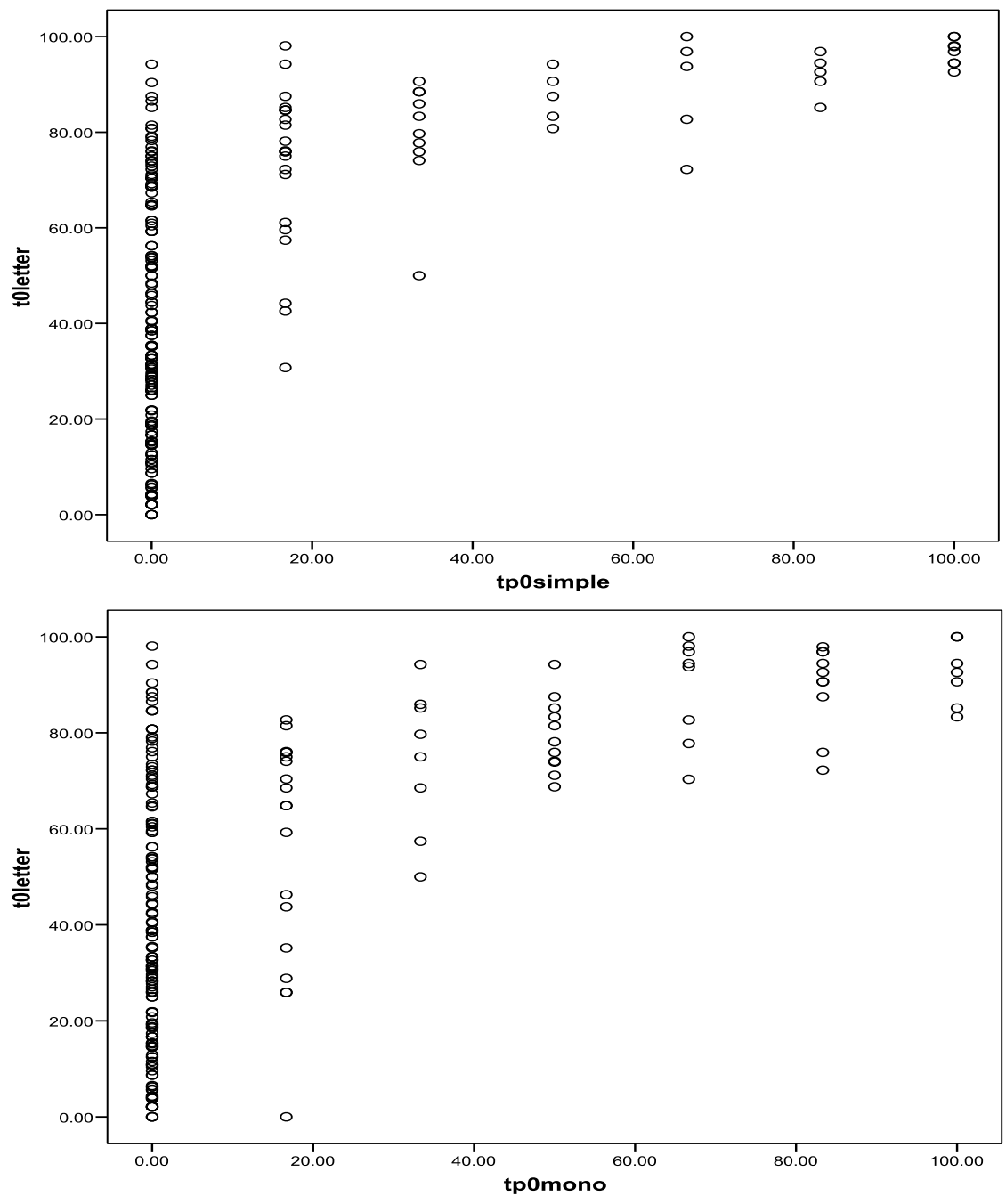
Examination of the scatter-plots between (upper- + lower-case) letter knowledge and phonemic skills is also instructive. Although regression indicates a significant relation for both matching and common unit identification (Figure 3, upper graphs), comparison with the scatter-plots for letter knowledge and simple word or nonsense word reading at the start of the school year (Figure 3, lower graphs) indicates that letter knowledge does not appear to be necessary for phonological awareness in the same way as it appears to be necessary for the development of simple reading skills. As in previous work, it appears that approximately $80 \%$ of letters need to be known before foundation reading skills advance (Duncan \& Seymour, 2000; Seymour \& Duncan, 2001).

\section{Summary Discussion}

Matching. Syllables were most salient in every language but a large-to-small sequence was not observed. Rimes and phonemes were responded to with equivalent accuracy in Icelandic, Portuguese, Spanish and French and phonemes were more salient than rimes in English and Greek. These languages groups also held when comparing accuracy for each unit, as English and Greek tended to be less accurate than all of the other languages at both syllable and rime matching. A different pattern was evident for phoneme matching as performance was lowest in French and highest in Icelandic.

Common Unit Identification. Three contrasting patterns of performance were apparent: (1) English and Icelandic - phonemes > syllables; (2) Greek and Portuguese - phonemes = syllables; and (3) French and Spanish - syllables $>$ phonemes. Rime identification was uniformly poor, either equivalent to phonemes (Portuguese, French, Spanish) or worse than phonemes (English, Icelandic, Greek). On syllable and rime 
identification, Spanish and French were consistently more accurate than English and Greek. The pattern for phonemes was very different as performance in English and Icelandic was more accurate than performance in French, Portuguese and Greek.

\section{Time 2: End of Grade 1}

Mean and standard deviations for the Raven's Matrices, Digit Span and Letter knowledge, Simple Word reading and Monosyllabic Nonword Naming can be found in Table 7.

Letter knowledge was at ceiling.....simple word reading without spanish and french, $F(3,156)=37.22, p<.001, \eta_{\mathrm{p}}{ }^{2}=.42($ English $<$ Portuguese, Icelandic $<$ Greek $)$ ....monosyllabic nonword naming without spanish and french, $F(3,156)=23.35, p<$ $.001, \eta_{\mathrm{p}}^{2}=.31($ English $=$ Portuguese $<$ Icelandic $=$ Portuguese $<$ Greek $)$ 
Table 7

Mean chronological ages, Ravens Progressive Matrices, Digit Span, letter knowledge, simple word reading and monosyllabic nonword naming of participants at Time 2 (standard deviations in parentheses)

\begin{tabular}{|c|c|c|c|c|c|c|c|c|}
\hline & Lang & lage & $\begin{array}{c}\text { CA } \\
\text { months }\end{array}$ & $\begin{array}{c}\text { Raven } \\
\text { s } \\
\text { s } \quad \text { raw } \\
\text { score }\end{array}$ & $\begin{array}{l}\text { Digit } \\
\text { Span } \\
\text { raw } \\
\text { score }\end{array}$ & $\begin{array}{r}\text { I } \\
\text { Knov } \\
\text { uppe }\end{array}$ & $\begin{array}{l}\text { Letter } \\
\text { wledge \% } \\
\text { lower }\end{array}$ & $\begin{array}{l}\text { simple } \\
\text { words }\end{array}$ \\
\hline English & 55 & $\begin{array}{l}71.41 \\
(3.13)\end{array}$ & $\begin{array}{l}18.00 \\
(3.94)\end{array}$ & $\begin{array}{c}6.56 \\
(1.71)\end{array}$ & $\begin{array}{l}94.73 \\
(8.72)\end{array}$ & $\begin{array}{l}92.17 \\
(9.85)\end{array}$ & $\begin{array}{c}56.21 \\
(25.97 \\
)\end{array}$ & $\begin{array}{c}60.91 \\
(31.13)\end{array}$ \\
\hline Greek & 50 & $\begin{array}{l}82.46 \\
(3.64)\end{array}$ & $\begin{array}{c}18.46 \\
(4.56)\end{array}$ & $\begin{array}{c}9.24 \\
(1.61)\end{array}$ & $\begin{array}{l}98.92 \\
(2.20)\end{array}$ & $\begin{array}{l}99.25 \\
(1.62)\end{array}$ & $\begin{array}{l}96.00 \\
(5.39)\end{array}$ & $\begin{array}{l}98.00 \\
(4.31)\end{array}$ \\
\hline Icelandic* & 33 & $\begin{array}{l}81.33 \\
(3.44)\end{array}$ & $\begin{array}{l}26.10 \\
(4.70)\end{array}$ & $\begin{array}{c}9.19 \\
(1.83)\end{array}$ & $\begin{array}{l}97.63 \\
(4.94)\end{array}$ & $\begin{array}{l}96.31 \\
(9.74)\end{array}$ & $\begin{array}{c}81.82 \\
(20.78 \\
)\end{array}$ & $\begin{array}{c}78.03 \\
(22.61)\end{array}$ \\
\hline $\begin{array}{l}\text { Portugues } \\
\text { e }\end{array}$ & 22 & $\begin{array}{l}83.45 \\
(3.79)\end{array}$ & $\begin{array}{l}18.23 \\
(4.72)\end{array}$ & $\begin{array}{c}8.00 \\
(1.31)\end{array}$ & $\begin{array}{l}87.17 \\
(5.11)\end{array}$ & $\begin{array}{l}88.91 \\
(5.31)\end{array}$ & $\begin{array}{c}78.16 \\
(19.37 \\
)\end{array}$ & $\begin{array}{c}68.94 \\
(26.25)\end{array}$ \\
\hline Spanish & 62 & & $\begin{array}{l}21.23 \\
(4.71)\end{array}$ & & & & $\sim 85 \%$ & \\
\hline French $^{\dagger}$ & 20 & & $\begin{array}{l}24.65 \\
(5.58)\end{array}$ & & $\begin{array}{c}92.20 \\
(12.48 \\
)\end{array}$ & $\begin{array}{c}88.08 \\
(10.13 \\
)\end{array}$ & $\sim 89 \%$ & \\
\hline
\end{tabular}

* Icelandic Digit Span was based on 31 participants

$\dagger$ Reading and Digit Span data were not available for French

Same-Different Judgement (Implicit Task)

Although the French children were close to ceiling in the syllable condition of this task (Table 8), a three-way analysis of variance was attempted in order to fully examine the accuracy results. There was one between-participants factor, language (English, Greek, Icelandic, Portuguese, Spanish, French), and two within-participants factors, Unit (syllable, rime, phoneme) and Structure (CVC, CV). Each main effect 
was significant (language: $F(5,236)=16.53, \mathrm{p}<.001, \eta_{\mathrm{p}}{ }^{2}=.26$; unit: $\mathrm{F}(2,472)=$ 151.21, $\mathrm{p}<.001, \eta_{\mathrm{p}}{ }^{2}=.39$; structure: $\left.\mathrm{F}(1,236)=38.29, \mathrm{p}<.001, \eta_{\mathrm{p}}{ }^{2}=.14\right)$ and all of the two-way interactions (unit by language: $\mathrm{F}(10,472)=5.12, \mathrm{p}<.001, \eta_{\mathrm{p}}{ }^{2}=.10$; unit by structure: $\left.F(2,472)=25.18, \mathrm{p}<.001, \eta_{\mathrm{p}}{ }^{2}=.10\right)$ with the exception of structure by language, $\mathrm{F}<1$. The interaction, unit by structure by language was also significant, $\mathrm{F}(10,472)=5.11, \mathrm{p}<.001, \eta_{\mathrm{p}}{ }^{2}=.10$, and will be investigated further using simple effects to investigate the effect of structure.

In English, performance was always significantly better with larger CVC structures, $F(1,54)=4.26, p<.05$. For the remaining languages, unit and structure interacted (Greek: $F(2,98)=3.65, p<.05$; Icelandic: $F(2,64)=7.24, p<.01$; Portuguese: $F(2,42)=11.07, p<.001$; Spanish: $F(2,122)=25.58, p<.001$; French: $F(2,38)=4.42, p<.05)$. Greek only showed an advantage for larger CVC structures for syllables, whereas, for Icelandic, Portuguese, Spanish and French the advantage for CVC structures was restricted to rimes. Little effect of structure emerged for phonemes except in Spanish, where phoneme matching was better in CV structures. Simple effects were also used to investigate the unit by language interaction. Only Portuguese showed no effect of unit (English: $F(2,108)=77.65, p<.001$; Greek: $F(2,98)=58.61, p<.001$; Icelandic: $F(2,64)=19.44, p<.001$; Spanish: $F(2$, $122)=55.04, p<.001$; French: $F(2,38)=20.28, p<.001)$. Rime matching was least accurate in each language. Greek, Icelandic and French showed no difference between syllables and phonemes, but accuracy was significantly higher with syllables than phonemes in English and Spanish (see Figure 4(a)). 
Table 8

Mean Percentage Accuracy for Same-Different Matching in each Language at Time 2 (Standard Deviations in Parentheses)

\begin{tabular}{|c|c|c|c|c|c|c|c|c|}
\hline \multirow[t]{2}{*}{ Time } & \multirow[t]{2}{*}{ Unit } & \multirow{2}{*}{$\begin{array}{l}\text { Structu } \\
\text { re }\end{array}$} & \multicolumn{6}{|c|}{ Language } \\
\hline & & & $\begin{array}{c}\text { Englis } \\
\mathrm{h} \\
(\mathrm{n}=55)\end{array}$ & $\begin{array}{l}\text { French } \\
(n=20)\end{array}$ & $\begin{array}{l}\text { Greek } \\
(\mathrm{n}=50)\end{array}$ & $\begin{array}{l}\text { Icelandic } \\
(n=33)\end{array}$ & $\begin{array}{c}\text { Portugues } \\
\text { e } \\
(n=22)\end{array}$ & $\begin{array}{c}\text { Spanish } \\
(\mathrm{n}=62)\end{array}$ \\
\hline \multicolumn{9}{|c|}{$\begin{array}{l}\text { End Of Grade } \\
1\end{array}$} \\
\hline & $\begin{array}{l}\text { Syllabl } \\
\mathrm{e}\end{array}$ & $\mathrm{CVC}$ & $\begin{array}{c}73.64 \\
(29.82 \\
)\end{array}$ & $\begin{array}{l}98.75 \\
(5.59)\end{array}$ & $\begin{array}{c}94.00 \\
(19.27)\end{array}$ & $\begin{array}{c}91.92 \\
(18.69)\end{array}$ & $\begin{array}{c}81.82 \\
(31.98)\end{array}$ & $\begin{array}{c}87.90 \\
(23.41)\end{array}$ \\
\hline & & $\mathrm{CV}$ & $\begin{array}{c}68.18 \\
(35.50 \\
)\end{array}$ & $\begin{array}{l}97.49 \\
(7.73)\end{array}$ & $\begin{array}{c}74.00 \\
(26.55)\end{array}$ & $\begin{array}{c}88.64 \\
(22.61)\end{array}$ & $\begin{array}{c}78.41 \\
(32.09)\end{array}$ & $\begin{array}{c}84.27 \\
(23.62)\end{array}$ \\
\hline & Rime & $\mathrm{CVC}$ & $\begin{array}{c}21.36 \\
(27.39 \\
)\end{array}$ & $\begin{array}{c}71.24 \\
(36.52)\end{array}$ & $\begin{array}{c}47.00 \\
(40.92)\end{array}$ & $\begin{array}{c}78.03 \\
(27.07)\end{array}$ & $\begin{array}{c}77.27 \\
(26.62)\end{array}$ & $\begin{array}{c}69.76 \\
(31.08)\end{array}$ \\
\hline & & $\mathrm{CV}$ & $\begin{array}{c}13.64 \\
(21.42 \\
)\end{array}$ & $\begin{array}{c}53.64 \\
(35.61)\end{array}$ & $\begin{array}{c}38.67 \\
(33.41)\end{array}$ & $\begin{array}{c}56.06 \\
(36.45)\end{array}$ & $\begin{array}{c}52.27 \\
(40.02)\end{array}$ & $\begin{array}{c}37.10 \\
(34.69)\end{array}$ \\
\hline & $\begin{array}{l}\text { Phone } \\
\text { me }\end{array}$ & CVC & $\begin{array}{c}59.09 \\
(38.30 \\
)\end{array}$ & $\begin{array}{c}88.74 \\
(15.13)\end{array}$ & $\begin{array}{c}80.00 \\
(33.50)\end{array}$ & $\begin{array}{c}89.39 \\
(18.90)\end{array}$ & $\begin{array}{c}73.86 \\
(29.36)\end{array}$ & $\begin{array}{c}66.13 \\
(29.37)\end{array}$ \\
\hline & & $\mathrm{CV}$ & $\begin{array}{c}58.64 \\
(39.45 \\
)\end{array}$ & $\begin{array}{c}83.68 \\
(18.74)\end{array}$ & $\begin{array}{c}77.00 \\
(28.35)\end{array}$ & $\begin{array}{c}87.12 \\
(24.30)\end{array}$ & $\begin{array}{c}82.95 \\
(28.23)\end{array}$ & $\begin{array}{c}79.03 \\
(27.61)\end{array}$ \\
\hline
\end{tabular}

The language groups differed in response to syllables, $F(5,236)=5.71, p<$. 001, with English and Portuguese being significantly worse than French. English was also worse than Icelandic, and the remaining languages overlapped with each of these groups. For rimes, English performance was weakest, followed by Greek, and Spanish overlapped both with Greek and with the remaining set of higher performers (French, Portuguese and Icelandic), $F(5,236)=20.76, p<.001$. For phonemes, English 
performed most poorly and Spanish was intermediate, overlapping with English and the remaining languages $(F(5,236)=6.88, p=.001)$. 
Figure 4: $\quad$ Percentage accuracy in phonological awareness tasks for each language group at the end of Grade 1: (a) Same-Different Task; (b) Common Unit task.

(a)

(b)
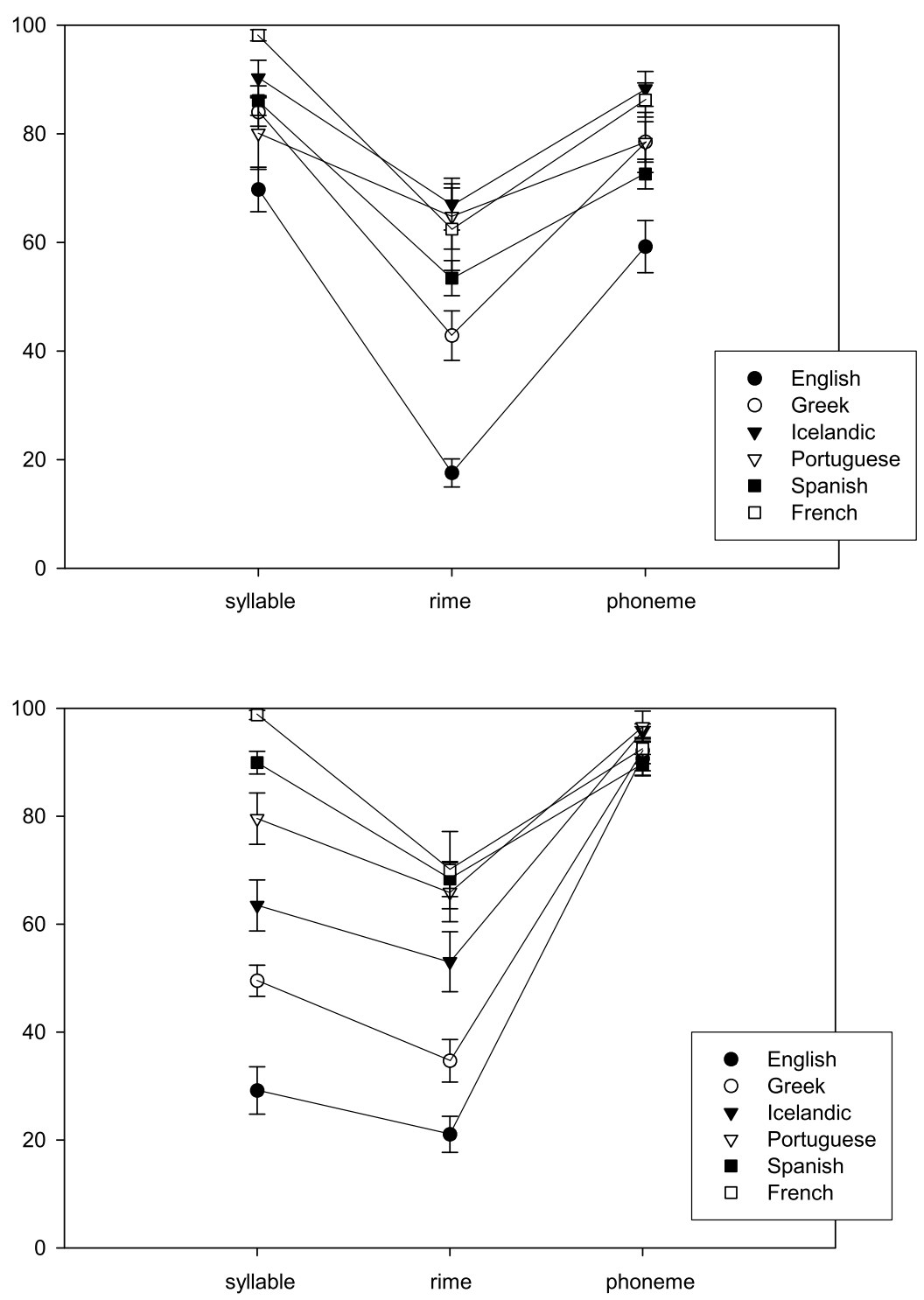
Common Unit Task

Table 9

Mean Percentage Accuracy for Common Unit Identification in each Language at

Time 2 (Standard Deviations in Parentheses)

\begin{tabular}{|c|c|c|c|c|c|c|}
\hline \multirow[t]{2}{*}{ Time } & \multirow[t]{2}{*}{ Unit } & \multirow{2}{*}{$\begin{array}{l}\text { Structur } \\
\mathrm{e}\end{array}$} & \multicolumn{4}{|c|}{ Language } \\
\hline & & & $\begin{array}{cc}\text { English } & \text { French } \\
(\mathrm{n}=55) & (\mathrm{n}=20)\end{array}$ & $\begin{array}{l}\text { Greek } \text { Icelandic } \\
(\mathrm{n}=50) \quad(\mathrm{n}=33)\end{array}$ & $\begin{array}{c}\text { Portuguese } \\
\quad(n=22)\end{array}$ & $\begin{array}{c}\text { Spanish } \\
(\mathrm{n}=62)\end{array}$ \\
\hline
\end{tabular}

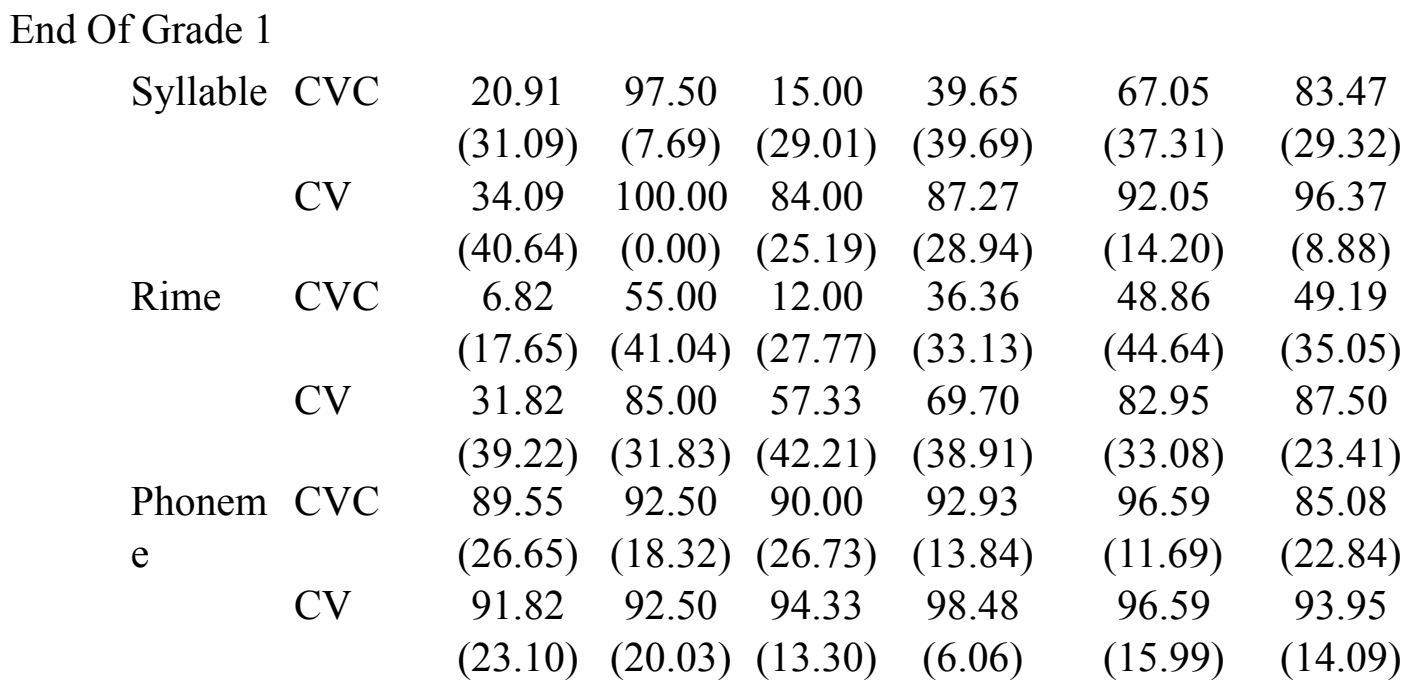

Inspection of Figure 4(b) reveals that all of the groups scored at ceiling in the phoneme condition of the Common Unit task by the end of Grade 1 (see also Table 9). An exploratory analysis was conducted on the remaining data in spite of the proximity to ceiling of the French and Spanish syllable responses because of the interest in completing the longitudinal comparison between all of the six languages in this task. The three-way analysis of variance had one between-participants factor, Language (English, Greek, Icelandic, Portuguese, Spanish, French), and two within-participants factors, Unit (syllable, rime) and Structure (CVC, CV). The main effects of Language, 
$F(5,236)=58.36, p<.001, \eta_{p^{2}}=.55$, unit, $F(1,236)=60.40, p<.001, \eta_{p^{2}}=.20$, and structure, $F(1,236)=267.00, p<.001, \eta_{\mathrm{p}}{ }^{2}=.53$, were significant. The interaction between unit and structure failed to achieve significance, $F(1,236)=3.11, p=.08$, but the remaining two-way interactions between structure and language, $F(5,236)=$ 13.76, $p<.001, \eta_{\mathrm{p}}{ }^{2}=.23$, and unit and language, $F(5,236)=2.22, p=.05, \eta_{\mathrm{p}}^{2}=.05$, were significant, as was the interaction between all three of the factors, $F(5,236)=$ $8.03, p<.001, \eta_{\mathrm{p}}^{2}=.15$

Simple effects were used on the three-way interaction to examine the influence of structure. Shared syllables and rimes were found to be significantly more salient in smaller CV structures in all languages. This effect was more pronounced for syllables than rimes in Greek, but the reverse was true for Spanish and French, although the performance of these latter groups was at ceiling for syllables (Greek: $F(1,49)=10.16, p<.01 ;$ Spanish, $F(1,61)=23.67, p<.001 ;$ French: $F(1,19)=$ $12.84, p<.01)$.

Breaking down the unit by language interaction using simple effects revealed an effect of unit (syllables $>$ rimes) for Greek, $F(1,49)=14.80, p<.001$, Portuguese, $F(1,21)=5.51, p<.05 ;$ Spanish, $F(1,61)=40.18, p<.001$, French, $F(1,19)=$ $15.93, p<.01$, and a marginal effect for Icelandic, $F(1,32)=3.84, p=.06$, but no effect for English. The language groups differed in their identification of shared syllables, $F(5,236)=57.04, p<.001$, and rimes, $F(5,236)=26.29, p<.001$. For syllables, English-speaking children were least accurate, followed by the Greek children, and the Spanish and French groups were most accurate. The Icelandic children showed some overlap in accuracy with the Greek children and the Portuguese group overlapped with the Spanish and French groups. For rimes, there were two 
main groups: English and Greek (low) versus Portuguese, Spanish and French (high).

Icelandic performance overlapped with both of these groups.

\section{Matching}

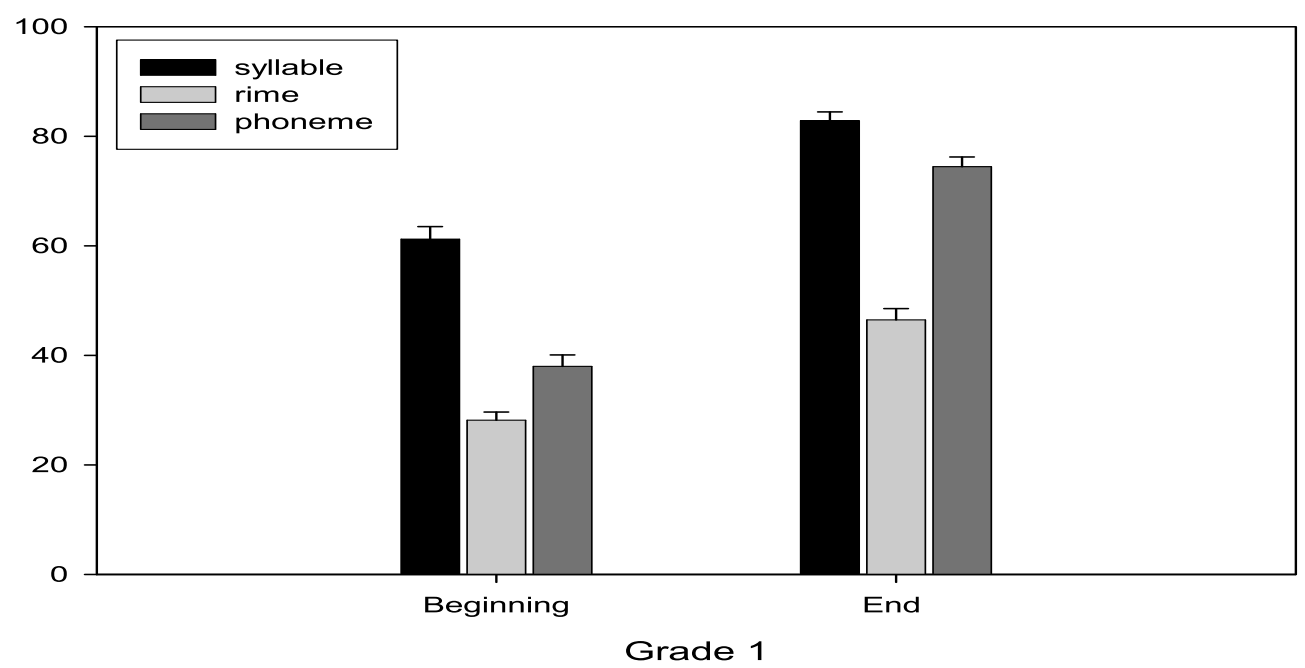

Common Unit

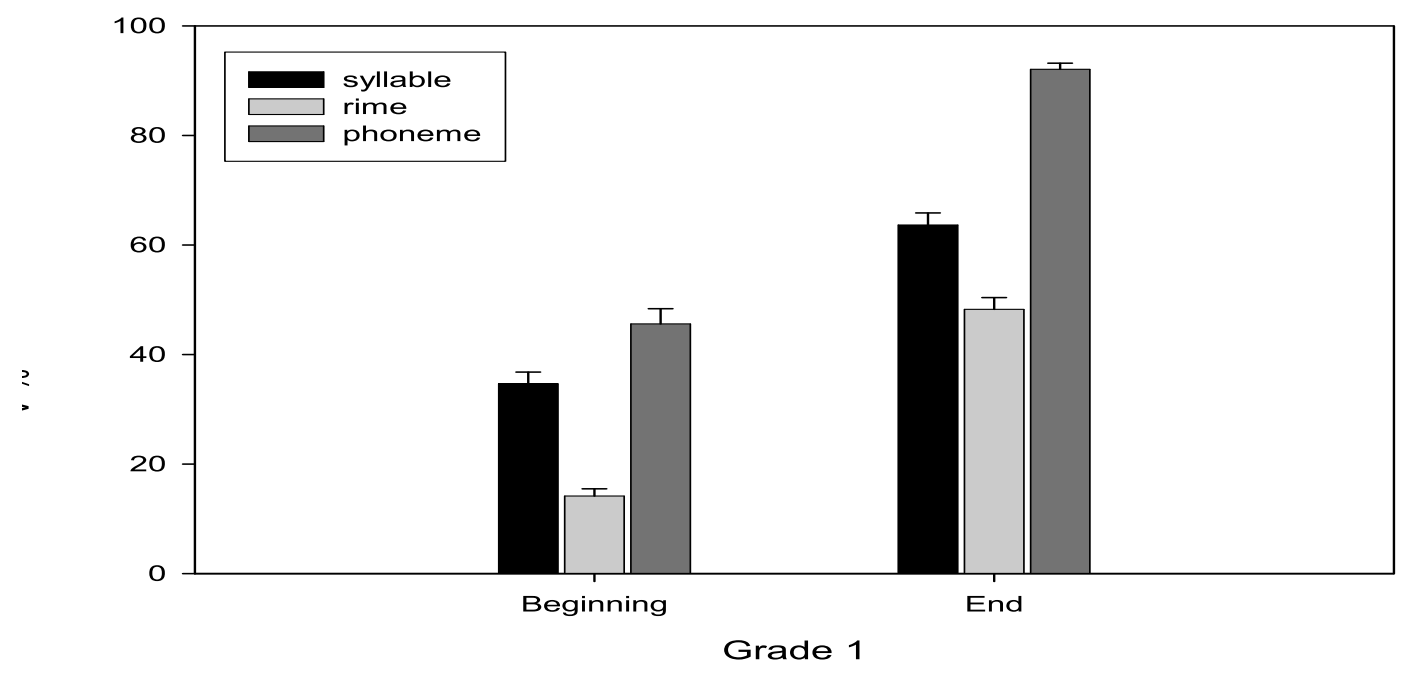


Summary Discussion

Matching. In Greek, Icelandic and French, syllable and phoneme matching was done with equivalent accuracy, whereas in English and Spanish, syllable matching remained easier than phoneme matching, but in all of these languages, rime matching proved most difficult. Portuguese was the only language to show no difference between any of the three sounds. In response to syllables, French was most accurate and English and Portuguese least accurate. English accuracy was lower than the other groups for phonemes. With rimes, French, Portuguese, and Icelandic were most accurate and English least accurate.

Common Unit Identification. Phoneme identification was at ceiling in every language. In Greek, Portuguese, Spanish and French, syllables were identified more accurately than rimes, whereas in English, syllable and rime identification were equivalent. Syllable identification was most accurate in Spanish and French and least accurate in English, and rime identification was most accurate in Portuguese, Spanish and French and least accurate in English and Greek.

\section{General Discussion}

The aim of this study was to examine: 1) the question of the availability of phonology in different languages at the outset of learning to read; and 2) the influence of orthography (granularity, consistency) in shaping phonological development during the first year of literacy acquisition.

Our first step was to examine performance in the two phonological tasks for evidence that a large-to-small progression was underway at the beginning of the first year of reading acquisition. What we observed was that performance varied according 
to both the task and the language under consideration. At each time point, an overall advantage emerged for large units in the matching task since initial syllables tended to be matched better than initial phonemes, but an overall advantage for small units was evident in the common unit task since phonemes were identified better than syllables; and, in both tasks, rimes within the first syllable were the least accessible unit.

However, there was also considerable variation due to language which did not appear to be linked to any ability or age differences between the language groups. For example, according to Lexical restructuring theory, the English-speakers who were a year younger than the other children, might have been expected to be at an earlier point in the large-to-small sequence than the other groups due to their age-appropriate but lower vocabulary skills, with the likelihood of delayed emergence of phoneme awareness. In the event, there were no indications of delay as the English-speakers were among the best performers in the phoneme conditions in contrast to their relative poor performance in the syllable conditions. These findings will be explored in more detail in the sections to follow.

\section{Availability of Phonology}

Syllables were the most salient sounds in every language at the beginning of the first school year in the matching task. The evidence was less clear, however, that this formed part of a large-small sequence of development. Rime and phoneme matching were either developing at a similar pace (Icelandic, Portuguese, Spanish, French) or phonemes were already more salient than rimes (English, Greek), strongly implying that it was not necessary for awareness of larger units to be complete for awareness of smaller units to emerge. 
Processing in the common unit task did not follow the same pattern since syllables were not always the easiest sounds to identify. Comparison with phonemes revealed three response patterns: (1) phonemes > syllables (English, Icelandic); (2) syllables $=$ phonemes (Greek, Portuguese); and (3) syllables $>$ phonemes $($ French, Spanish). Rime identification was uniformly poor, either equivalent to phonemes (Portuguese, French, Spanish) or worse than phonemes (English, Icelandic, Greek).

These results argue against Metsala and Walley's (1998) suggestion that there should be a "relation in performance across implicit and explicit tasks for specific items" (p. 102), since the same stimuli were used in our implicit and explicit tasks. The outcome at each time point was also less than consistent with Gombert's (1992) prediction that implicit sensitivity to any sound is necessary for explicit awareness of that sound. The prediction worked best for syllables where implicit performance tended to be better or similar to explicit performance. However, performance levels for rimes were similar in both tasks and implicit abilities were relatively poor compared to explicit skills for phonemes, especially at the end of Grade 1.

The contrasting outcomes in the two tasks tie in with proposals that phonological tasks may tap different levels of awareness depending on their demands (Morais et al, 1987; Bertelson \& de Gelder, 1989, 1991; Morais, 1991; Gombert; 1992). Savage et al (2006) observed a similar large-unit advantage in a matching task and a small-unit advantage in the common-unit task for English-speakers prior to school entry. Their conclusion was that the epilinguistic awareness required for matching may be related to the quality of children's acoustic-phonetic representations and that the metalinguistic awareness required for common-unit identification may be related to the quality of articulatory-phonetic representations, and while this proposal awaits confirmation, it is at least consistent with the present evidence. Holistic 
sensitivity to sound appeared sufficient for sound matching as larger units of sound were most salient, in keeping with the relevance of unit size rather than linguistic status, and cross-linguistic variation was relatively small as might be expected from a task which does not demand precision in identification or articulation. In contrast, the analysis required by the common unit task appeared to expose considerable variation between languages.

The presence of cross-linguistic variation also answers our initial question regarding the existence of a universal sequence of phonological development. Of interest is whether this variation is consistent with a syllable complexity explanation or one due to the rhythmic characteristics of the languages. In the syllable tasks, English and Greek tended to be less accurate than the other languages at matching and identification, and Spanish and French tended to be among the most accurate. Thus, the results contradict the syllable structure prediction of a syllable processing advantage for Portuguese where syllables are simplest in structure. Instead, the findings were most consistent with an account emphasising speech rhythm as syllable processing was worse in the stress-timed language, English, than in French and Spanish, which have syllable-timed rhythm.

A common feature of performance in both tasks was the generally low levels of rime awareness. This contrasts with the wealth of evidence that onset-rime structure is salient from preschool onwards (e.g. Treiman, 1985; Kirtley, Bryant, Maclean \& Bradley, 1989). Nevertheless, this evidence derives mainly from studies using English monosyllabic stimuli, raising questions about how such findings translate to a multi-syllabic context, which is more typical of other European languages and which was used by necessity for cross-linguistic comparison in the present study. Duncan et al (2007) explored this issue in relation to English rhyming 
skill and discovered that evidence favoured the division of disyllabic words like "rocket" into an onset plus superrime structure (/r/-/pkit/) rather than an organisation in which the onset and rime of each syllable was salient $([/ \mathrm{r} /-/ \mathrm{b} /]-[/ \mathrm{k} /-/ \mathrm{It} /])$. The rime of the first syllable also has a relatively low level of salience in the other European languages in the present study, although cross-linguistic variation in the degree of segmental awareness of the rime appeared to follow a similar pattern to syllable awareness.

\section{Influence of Orthography}

Syllable and rime identification in the common unit task improved during the first school year but the relative position of the language groups remained much the same as it had been at the beginning of the year, suggesting that literacy had not exerted a differential effect on performance. Syllable identification was most accurate in Spanish and French and least accurate in English. Once again, this outcome is most consistent with an explanation based on speech rhythm rather than syllable structure since syllable processing was best in French and Spanish (syllable-timed) and worst in English (stress-timed).

By the end of the year, letter knowledge was at ceiling in all of the languages with the possible exception of Portuguese. This was mirrored in ceiling performance for phoneme identification in every language. Phoneme matching lagged behind this level especially in English and Spanish, where phoneme matching still remained significantly more difficult than syllable matching. This casts further doubt on Gombert's (1992) assertion that implicit sensitivity to a sound is a necessary precursor of metalinguistic awareness of that sound, and further emphasises the possibility of 
different outcomes when different tasks are used to measure awareness of a particular sound.

The extent of cross-language variation was once again smaller in the matching than the identification task. Nonetheless, the English group proved poor at matching relative to the other, older, children and this difference was more pronounced than it had been at the start of the school year since the English-speakers were now the least accurate in every condition. This low level of performance, however, did not extend to the phoneme condition of the common unit task where the young English-speakers performed at ceiling and were indistinguishable from the other language groups.

The Psycholinguistic Grain Size model predicts that the emergence of phoneme awareness may be accelerated in shallow relative to deeper orthographies (Greek, Spanish, Icelandic $>$ Portuguese $>$ French $>$ English). Tests of simple word and monosyllabic nonword reading showed that performance at the end of the first school year broadly confirmed the influence of orthographic depth on reading acquisition (see Table 7). With phoneme awareness, however, evidence did not correspond with this analysis since the two most advanced groups in terms of phoneme identification at Time 1 were readers of the English (deep) and Icelandic (shallow) orthographies; moreover, by Time 2, ceiling-level phoneme identification was already observable across all the language groups.

Instead, a regression analyses indicated a robust link between phoneme awareness and letter knowledge at Time 1. Letter knowledge explained a significant amount of variance in both phoneme $\left(\Delta \mathrm{R}^{2}=18 \%\right)$ and syllable matching $\left(\Delta \mathrm{R}^{2}=7 \%\right)$ even after controlling for Ravens matrices and Digit Span, but was related only to phoneme identification $\left(\Delta \mathrm{R}^{2}=25 \%\right)$ in the Common Unit task. In agreement with the work of Hulme et al (2005a), this link does not appear to be one of strict dependence 
and this contrasts markedly with the situation for simple word reading and nonword decoding where letter knowledge has to reach around $80 \%$ before substantial progress can be made (see Figure 3).

Overview 
References

Abercrombie, D. (1967). Elements of general phonetics. Edinburgh: Edinburgh University Press.

Aidinis, A., \& Nunes, T. (2001). The Role of Different Levels of Phonological Awareness in the Development of Reading and Spelling in Greek. Reading and Writing, 14(1-2), 145-177.

Anthony, J. L., \& Francis, D. J. (2005). Development of phonological awareness. Current Directions in Psychological Science, 14(5), 255-259.

Anthony, J. L., Lonigan, C. J., Driscoll, K., Phillips, B. M., \& Burgess, S. R. (2003). Phonological sensitivity: A quasi-parallel progression of word structure units and cognitive operations. Reading Research Quarterly, 38(4), 470-487.

Arvaniti, A. (1994). Acoustic Features of Greek Rhythmic Structure. Journal of Phonetics, 22(3), 239-268.

Arvaniti, A. (2007). Greek phonetics: The state of the art. Journal of Greek Linguistics, 8, 97-208.

Arvaniti, A. (2009). Rhythm, Timing and the Timing of Rhythm. Phonetica, 66(1-2), 46-63.

Baltazani, M. (2007). Prosodic rhythm and the status of vowel reduction in Greek. Selected Papers on Theoretical and Applied Linguistics from the 17th International Symposium on Theoretical \& Applied Linguistics, Vol. 1, 31-43. Department of Theoretical and Applied Linguistics, Thessaloniki.

Barron, R.W. (1991). Proto-literacy, literacy, and the acquisition of phonological awareness, Learning and Individual Differences 3: 243-255.

Bertelson, P., \& De Gelder, B. (1989). Learning about Reading from Illiterates. In A. M. Galaburda (Ed.), From Reading to Neurons (pp. 1-25). Cambridge Ma.: M.I.T. press.

Bertelson, P., \& D Gelder, B. (1991). The Emergence of Phonological Awareness: Comparative Approaches. In I. G. Mattingly \& M. Studdart-Kennedy (Eds.), Modularity and the Motor Theory of Speech Perception (pp. 393-412): Hillsdale, NJ.

Bertelson, P., de Gelder, B., \& van Zon, M. (1997). Explicit speech segmentation and syllabic onset structure: Developmental trends. Psychological Research, 60(3), 183-191.

Borgwaldt, S.R., Hellwig, F.M., \& De Groot, A.M.B. (2005). Onset entropy matters Letter-to-phoneme mappings in seven languages. Reading and Writing, 18, 211229.

Bowey, J. A., \& Underwood, N. (1996). Further evidence that orthographic rime usage in nonword reading increases with word-level reading proficiency. Journal of Experimental Child Psychology, 63(3), 526-562.

Bradley, L., \& Bryant, P. E. (1983). Categorizing Sounds and Learning to Read - a Causal Connection. Nature, 301(5899), 419-421.

Brown, G. D. A., \& Deavers, R. P. (1999). Units of analysis in nonword reading: Evidence from children and adults. Journal of Experimental Child Psychology, 73(3), 208-242.

Bruce, D. J. (1964). The Analysis of Word Sounds by Young Children. British Journal of Educational Psychology, 34, 158-170. 
Bus, A. G., \& van Ijzendoorn, M. H. (1999). Phonological awareness and early reading: A meta-analysis of experimental training studies. Journal of Educational Psychology, 91(3), 403-414.

Caravolas, M., \& Bruck, M. (1993). The Effect of Oral and Written Language Input On Childrens Phonological Awareness - a Cross-Linguistic Study. Journal of Experimental Child Psychology, 55(1), 1-30.

Caravolas, M., Volin, J., \& Hulme, C. (2005). Phoneme awareness is a key component of alphabetic literacy skills in consistent and inconsistent orthographies: Evidence from Czech and English children. Journal of Experimental Child Psychology, 92(2), 107-139.

Carroll, J. M., Snowling, M. J., Hulme, C., \& Stevenson, J. (2003). The development of phonological awareness in preschool children. Developmental Psychology, 39(5), 913-923.

Castles, A., \& Coltheart, M. (2004). Is there a casual link from phonological awareness to success in learning to read? Cognition, 91, 77-111.

Castles, A., Coltheart, M., Wilson, K., Valpied, J., \& Wedgwood, J. (2009). The genesis of reading ability: What helps children learn letter-sound correspondences? Journal of Experimental Child Psychology, 104(1), 68-88.

Content, A., Kolinsky, R., Morais, J., \& Bertelson, P. (1986). Phonetic Segmentation in Prereaders - Effect of Corrective Information. Journal of Experimental Child Psychology, 42(1), 49-72.

Cossu, G., Shankweiler, D., Liberman, I. Y., Katz, L., \& Tola, G. (1988). Awareness of Phonological Segments and Reading-Ability in Italian Children. Applied Psycholinguistics, 9(1), 1-16.

Dauer, R. M. (1980). Stress and Rhythm in Modern Greek. Doctoral dissertation, University of Edinburgh.

Dauer, R. M. (1983). Stress-Timing and Syllable-Timing Reanalyzed. Journal of Phonetics, 11(1), 51-62.

De Cara, B., \& Goswami, U. (2003). Phonological neighbourhood density: effects in a rhyme awareness task in five-year-old children. Journal of Child Language, 30(3), 695-710.

De Jong, P. F., \& Van der Leij, A. (2003). Developmental Changes in the Manifestation of a Phonological Deficit in Dyslexic Children Learning to Read a Regular Orthography. Journal of Educational Psychology, 95(1), 22-40.

Demont, E., \& Gombert, J. E. (1996). Phonological awareness as a predictor of recoding skills and syntactic awareness as a predictor of comprehension skills. British Journal of Educational Psychology, 66, 315-332.

Duncan, L. G., Cole, P., Seymour, P. H. K., \& Magnan, A. (2006). Differing sequences of metaphonological development in French and English. Journal of Child Language, 33(2), 369-399.

Duncan, L. G., Seymour, P. H. K., \& Bolik, F. (2007). Rimes and superrimes: An exploration of children's disyllabic rhyming skills. British Journal of Psychology, 98, 199-221.

Duncan, L. G., Seymour, P. H. K., \& Hill, S. (1997). How important are rhyme and analogy in beginning reading? Cognition, 63(2), 171-208.

Duncan, L. G., Seymour, P. H. K., \& Hill, S. (2000). A small-to-large unit progression in metaphonological awareness and reading? Quarterly Journal of Experimental Psychology Section a-Human Experimental Psychology, 53(4), 1081-1104. 
Durgunoglu, A. Y., \& Oney, B. (1999). A cross-linguistic comparison of phonological awareness and word recognition. Reading and Writing, 11(4), 281-299.

Ehri, L.C. (1992). Reconceptualizing the development of sight word reading and its relationship to recoding. In P. Gough, L.C. Ehri, \& R. Treiman (Eds.), Reading acquisition. Hillsdale, NJ: Erlbaum.

Ehri, L. C., \& Robbins, C. (1992). Beginners Need Some Decoding Skill to Read Words By Analogy. Reading Research Quarterly, 27(1), 12-26.

Elbro, C., Borstrom, I., \& Petersen, D. K. (1998). Predicting dyslexia from kindergarten: The importance of distinctness of phonological representations of lexical items. Reading Research Quarterly, 33(1), 36-60.

Fenk-Oczlon, G., \& Fenk, A. (1999). Cognition, quantitative linguistics, and systemic typology. Linguistic Typology, 3, 151-177.

Ferguson, C. A., \& Farwell, C. B. (1975). Words and Sounds in Early Language Acquisition. Language, 51(2), 419-439.

Fowler, A. E. (1991). How Early Phonological Development Might set the Stage for Phoneme Awareness. In S. A. Brady \& D. P. Shankweiler (Eds.), Phonological Processes in Literacy (pp. 97 - 117).

Foy, J. G., \& Mann, V. A. (2009). Effects of onset density in preschool children: Implications for development of phonological awareness and phonological representation. Applied Psycholinguistics, 30(2), 339-361.

Frost, R., Katz, L., \& Bentin, S. (1987). Strategies for Visual Word Recognition and Orthographical Depth: A Multilingual Comparison. Journal of Experimental Psychology, 13(1), 104-115.

Frota, S., \& Vigário, M. (2001). On the correlates of rhythmic distinctions: The European/Brazilian Portuguese case. Probus, 13, 247-275.

Garlock, V. M., Walley, A. C., \& Metsala, J. L. (2001). Age-of-Acquisition, Word Frequency, and Neighborhood Density Effects on Spoken Word Recognition by Children and Adults. Journal of Memory and Language, 45, 468-492.

Geudens, A., \& Sandra, D. (2003). Beyond implicit phonological knowledge: No support for an onset-rime structure in children's explicit phonological awareness. Journal of Memory and Language, 49(2), 157-182.

Geudens, A., Sandra, D., \& Van den Broeck, W. (2004). Segmenting two-phoneme syllables: Developmental differences in relation with early reading skills. Brain and Language, 90(1-3), 338-352.

Geudens, A., Sandra, D., \& Martensen, H. (2005). Rhyming words and onset-rime constituents: An inquiry into structural breaking points and emergent boundaries in the syllable. Journal of Experimental Child Psychology, 92(4), 366-387.

Goikoetxea, E. (2005). Levels of phonological awareness in preliterate and literate Spanish-speaking children. Reading and Writing, 18, 51-79.

Gombert, J. E. (1992). Metalinguistic Development. New York: Harvester Wheatsheaf.

Goswami, U. (1990). A Special Link Between Rhyming Skill and the Use of Orthographic Analogies By Beginning Readers. Journal of Child Psychology and Psychiatry and Allied Disciplines, 31(2), 301-311.

Goswami, U. (1991). Learning About Spelling Sequences - the Role of Onsets and Rimes in Analogies in Reading. Child Development, 62(5), 1110-1123.

Goswami, U., \& Bryant, P.E. (1990). Phonological skills and learning to read. Hillsdale, NJ: Erlbaum. 
Goswami, U., \& East, M. (2000). Rhyme and analogy in beginning reading: Conceptual and methodological issues. Applied Psycholinguistics, 21(1), 63-93.

Goswami, U., Gombert, J. E., \& de Barrera, L. F. (1998). Children's orthographic representations and linguistic transparency: Nonsense word reading in English, French, and Spanish. Applied Psycholinguistics, 19(1), 19-52.

Goswami, U., \& Mead, F. (1992). Onset and Rime Awareness and Analogies in Reading. Reading Research Quarterly, 27(2), 152-162.

Goswami, U., Porpodas, C., \& Wheelwright, S. (1997). Children's orthographic representations in English and Greek. European Journal of Psychology of Education, 12(3), 273-292.

Goswami, U., Ziegler, J. C., Dalton, L., \& Schneider, W. (2001). Pseudohomophone effects and phonological recoding procedures in reading development in English and German. Journal of Memory and Language, 45(4), 648-664.

Goswami, U., Ziegler, J. C., Dalton, L., \& Schneider, W. (2003). Nonword reading across orthographies: How flexible is the choice of reading units? Applied Psycholinguistics, 24(2), 235-247.

Grabe, E., \& Low, E.L. (2002). Durational Variability in Speech and the Rhythm Class Hypothesis. Papers in Laboratory Phonology 7, Mouton. de Gruyter.

Green, D. M., \& Swets, J. A. (1966). Signal detection theory and psychophysics. New York: John Wiley and Sons.

Harm, M. W., \& Seidenberg, M. S. (1999). Phonology, Reading Acquisition, and Dyslexia: Insights from Connectionist Models. Psychological Review, 106(3), 491-528.

Harris, M., \& Giannouli, V. (1999). Learning to read and spell in Greek: The importance of letter knowledge and morphological awareness. In M. Harris \& G. Hatano (Eds.), Learning to read and write: A cross-linguistic perspective (pp. 51-70). Cambridge: Cambridge University Press.

Hayes, B. (1985). A Metrical Theory of Stress Rules, Garland Press, New York.

Hulme, C., Caravolas, M., Malkova, G., \& Brigstocke, S. (2005a). Phoneme isolation ability is not simply a consequence of letter-sound knowledge. Cognition, 97(1), B1-B11.

Hulme, C., Snowling, M., Caravolas, M., \& Carroll, J. (2005b). Phonological skills are (probably) one cause of success in learning to read: A comment on Castles and Coltheart. Scientific Studies of Reading, 9(4), 351-365.

Johnson, K., \& Sinsabaugh, B. (1985). The simplification of the Greek vowel system. Chicago Linguistic Society, 21, 189-198.

Jusczyk, P. W. (1986). Toward a model of the development of speech perception. In J. S. Perkell \& D. H. Klatt (Eds.), Imariance and variability in speech processes (pp. 1-19). Hillsdale, NJ: Erlbaum.

Karmiloff-Smith, A. (1986). From Meta-Processes to Conscious Access - Evidence From Childrens Metalinguistic and Repair Data. Cognition, 23(2), 95-147.

Kim, J., Davis, C., \& Cutler, A. (2008). Perceptual Tests of Rhythmic Similarity: II. Syllable Rhythm. Language and Speech, 51(4), 343-359.

Kirtley, C., Bryant, P., Maclean, M., \& Bradley, L. (1989). Rhyme, Rime, and the Onset of Reading. Journal of Experimental Child Psychology, 48(2), 224-245.

Kohler, K. J. (2009a). Whither Speech Rhythm Research? Phonetica, 66(1-2), 5-14.

Kohler, K. J. (2009b). Rhythm in Speech and Language A New Research Paradigm. Phonetica, 66(1-2), 29-45. 
Lee, C. S., \& Todd, N. P. M. (2004). Towards an auditory account of speech rhythm: application of a model of the auditory 'primal sketch' to two multi-language corpora. Cognition, 93(3), 225-254.

Lehiste, I. (1977). Isochrony reconsidered. Journal of Phonetics, 5, 253-263.

Lenel, J. C., \& Cantor, J. H. (1981). Rhyme Recognition and Phonemic Perception in Young-Children. Journal of Psycholinguistic Research, 10(1), 57-67.

Liberman, I. Y., Shankweiler, D., Fischer, F. W., \& Carter, B. (1974). Explicit Syllable and Phoneme Segmentation in the Young Child. Journal of Experimental Child Psychology, 18, 201-212.

Mann, V., \& Wimmer, H. (2002). Phoneme awareness and pathways into literacy: A comparison of German and American children. Reading and Writing, 15, 653682.

McBride-Chang, C., Wagner, R. K., \& Chang, L. (1997). Growth modeling of phonological awareness. Journal of Educational Psychology, 89(4), 621-630.

Mehler, J., Dommergues, J. Y., Frauenfelder, U., \& Segui, J. (1981). The Syllables Role in Speech Segmentation. Journal of Verbal Learning and Verbal Behavior, 20(3), 298-305.

Mennen, I. and Okalidou, A. (2006). Acquisition of Greek phonology: an overview. QMUC Speech Science Research Centre Working Papers, WP-11.

Menyuk, P. \& Menn, L. (1979). Perception and production of phonemic contrasts. In P. Fletcher \& M. Garman (Eds.), Studies in Language Acquisition (pp. 49-70). Cambridge, UK: Cambridge University Press.

Metsala, J. L. (1999). Young Children's Phonological Awareness and Nonword Repetition as a Function of Vocabulary Development. Journal of Educational Psychology, 91(1), 3-19.

Metsala, J. L., Stavrinos, D., \& Walley, A. C. (2009). Children's spoken word recognition and contributions to phonological awareness and nonword repetition: A 1-year follow-up. Applied Psycholinguistics, 30(1), 101-121.

Metsala, J. L., \& Walley, A. C. (1998). Spoken vocabulary growth and the segmental restructuring of lexical representations: Precursors to phonemic awareness and early reading ability. In J. L. Metsala \& L. C. Ehri (Eds.), Word recognition in beginning literacy (pp. 89-120). Mahwah, NJ: Erlbaum.

Morais, J. (1991). Constraints on the Development of Phonemic Awareness. In S. A. Bradey \& D. P. Shankweiler (Eds.), Phonological Processes In Literacy (pp. 5 -27). Hillsdale, NJ: Erlbaum.

Morais, J., Alegria, J., \& Content, A. (1987). The Relationships Between Segmental Analysis And Alphabetic Literacy: An Interactive View. Cahiers de Psychologie Cognitive / European Bulletin of Psychology, 7(5), 415 - 438.

Morais, J., Castro, S. L., Scliarcabral, L., Kolinsky, R., \& Content, A. (1987). The Effects of Literacy on the Recognition of Dichotic Words. Quarterly Journal of Experimental Psychology Section a-Human Experimental Psychology, 39(3), 451-465.

Murty, L., Otake, T., \& Cutler, A. (2007). Perceptual Tests of Rhythmic Similarity: I. Mora Rhythm. Language and Speech, 50(1), 77-99.

Muter, V., Snowling, M., \& Taylor, S. (1994). Orthographic Analogies and Phonological Awareness - Their Role and Significance in Early Reading Development. Journal of Child Psychology and Psychiatry and Allied Disciplines, 35(2), 293-310. 
Nazzi, T., Bertoncini, J., \& Mehler, J. (1998). Language discrimination by newborns: Toward an understanding of the role of rhythm. Journal of Experimental Psychology-Human Perception and Performance, 24(3), 756-766.

Niebuhr, O. (2009). F-0-Based Rhythm Effects on the Perception of Local Syllable Prominence. Phonetica, 66(1-2), 95-112.

Niessen, M., Frith, U., Reitsma, P., \&O” hngren, B. (2000). Learning disorders as a barrier to human development $1995-1999$. Evaluation report. Technical Committee COST Social Sciences.

Patel, T. K., Snowling, M. J., \& de Jong, P. F. (2004). A cross-linguistic comparison of children learning to read in English and Dutch. Journal of Educational Psychology, 96(4), 785-797.

Perfetti, C. A., Beck, I., Bell, L. C., \& Hughes, C. (1987). Phonemic Knowledge and Learning to Read Are Reciprocal - a Longitudinal-Study of 1st-Grade Children. Merrill-Palmer Quarterly-Journal of Developmental Psychology, 33(3), 283-319.

Ramus, F., Nespor, M., \& Mehler, J. (1999). Correlates of linguistic rhythm in the speech signal. Cognition, 73(3), 265-292.

Read, C. (1978). Children's Awareness of Language with Emphasis on Sound Systems. In A. Sinclair, R. J. Jarvella \& W. J. M. Levelt (Eds.), The Child's Conception of Language (pp. 65-82). Berlin: Springer-Verlag.

Johnson, K. \& Sinsabaugh, B. (1985) The simplification of the Greek vowel system. Chicago Linguistic Society. 21: 189-198.

Savage, R., Blair, R., \& Rvachew, S. (2006). Rimes are not necessarily favored by prereaders: Evidence from meta- and epilinguistic phonological tasks. Journal of Experimental Child Psychology, 94(3), 183-205.

Seymour, P. H. K., Aro, M., Erskine, J. M., Wimmer, H., Leybaert, J., Elbro, C., et al. (2003). Foundation literacy acquisition in European orthographies. British Journal of Psychology, 94, 143-174.

Seymour, P.H.K., Duncan, L.G. \& Bolik, F.M. (1999). Rhymes and phonemes in the common unit task: Replications and implications for beginning reading. Journal of Research in Reading, 22 (2), 113-130.

Seymour, P. H. K., \& Evans, H. M. (1994). Levels of Phonological Awareness and Learning to Read. Reading and Writing, 6(3), 221-250.

Stone, G. O., Vanhoy, M., \& VanOrden, G. C. (1997). Perception is a two-way street: Feedforward and feedback phonology in visual word recognition. Journal of Memory and Language, 36(3), 337-359.

Treiman, R. (1985). Onsets and Rimes As Units of Spoken Syllables - Evidence From Children. Journal of Experimental Child Psychology, 39(1), 161-181.

Treiman, R. (1987). On the Relationship between Phonological Awareness and Literacy. Cahiers De Psychologie Cognitive-Current Psychology of Cognition, 7(5), 524-529.

Treiman, R. (1992). The Role of intrasyllabic units in learning to read and spell. In P. B. Gough, L. C. Ehri \& R. Treiman (Eds.), Reading Acquisition (pp. 1-70). Hillsdale, NJ.: Erlbaum.

Treiman, R., Mullennix, J., Bijeljac-Babic, R., \& Richmond-Welty, E. D. (1995). The Special Role of Rimes in the Description, Use, and Acquisition of English Orthography. Journal of Experimental Psychology-General, 124(2), 107-136. 
Treiman, R., \& Zukowski, A. (1991). Levels of Phonological Awareness. In S. A. Brady \& D. P. Shankweiler (Eds.), Phonological processes in literacy: A tribute to Isabelle Y Liberman (pp. 67 - 83). Hillsdale, NJ: Erlbaum.

Treiman, R., \& Zukowski, A. (1996). Children's sensitivity to syllables, onsets, rimes and phonemes. Journal of Experimental Child Psychology, 61, 193-215.

Ventura, P., Kolinsky, R., Fernandes, S., Querido, L., \& Morais, J. (2007). Lexical restructuring in the absence of literacy. Cognition, 105(2), 334-361.

Ventura, P., Morais, J., \& Kolinsky, R. (2007). The development of the orthographic consistency effect in speech recognition: From sublexical to lexical involvement. Cognition, 105(3), 547-576.

Vicente, S., Castro, S.L., \& Walley, A. (2003). A developmental analysis of similarity neighborhoods in European Portuguese. Journal of Portuguese Linguistics, 2, 93-114.

Wagner, R. K., Torgesen, J. K., \& Rashotte, C. A. (1994). Development of ReadingRelated Phonological Processing Abilities - New Evidence of Bidirectional Causality From a Latent Variable Longitudinal-Study. Developmental Psychology, 30(1), 73-87.

Walley, A. C. (1993). The Role of Vocabulary Development in Childrens Spoken Word Recognition and Segmentation Ability. Developmental Review, 13(3), 286-350.

Wioland, F. (1985). Les structures syllabiques du français. Genève: Slatkine; Paris : Champion.

Yopp, H. K. (1988). The Validity and Reliability of Phonemic Awareness Tests. Reading Research Quarterly, 23(2), 159-177.

Ziegler, J. C., \& Ferrand, L. (1998). Orthography shapes the perception of speech: The consistency effect in auditory word recognition. Psychonomic Bulletin \& Review, 5(4), 683-689.

Ziegler, J. C., \& Goswami, U. (2005). Reading acquisition, developmental dyslexia, and skilled reading across languages: A psycholinguistic grain size theory. Psychological Bulletin, 131(1), 3-29.

Ziegler, J. C., Jacobs, A. M., \& Stone, G. O. (1996). Statistical analysis of the bidirectional inconsistency of spelling and sound in French. Behavior Research Methods Instruments \& Computers, 28(4), 504-515.

Ziegler, J. C., Stone, G. O., \& Jacobs, A. M. (1997). What is the pronunciation for ough and the spelling for vertical bar u vertical bar? A database for computing feedforward and feedback consistency in English. Behavior Research Methods Instruments \& Computers, 29(4), 600-618. 